\title{
Avaliação dos Volumes de Espera Requeridos no Sistema Cantareira
}

\author{
Luís Antonio Villaça de Garcia*, Silvana Susko Marcellini, Arnaldo Sérgio Kutner \\ susko@uol.com.br, ksa386@uol.com.br
}

Rubem La Laina Porto

Escola Politécnica da USP

rlporto@usp.br

Recebido:14/11/09 - revisado: 21/04/10 - aceito: 06/07/11

\begin{abstract}
RESUMO
Este trabalho apresenta os estudos hidrológico-operacionais para avaliação dos volumes de espera dos aproveitamentos do Sistema Cantareira considerando a segurança hidrológica das barragens e as vazões de restrição a jusante. Os hidrogramas de projeto para esta avaliação foram determinados pela aplicação de modelo chuva-vazão utilizando tormentas com periodos de retorno entre 2 e 1.000 anos. As características fisiográficas foram determinadas utilizando as bases cartográficas, a análise pedológica detalhada e o uso e ocupação do solo por imagens. Foi desenvolvida a modelagem matemáticocomputacional para simulações da operação dos reservatórios para o controle de cheias considerando as vazões de restrição a jusante e hidrogramas com periodo de retorno de 100 anos e para garantir a segurança das barragens utilizando hidrogramas com periodo de retorno de 1.000 anos. Para determinação dos volumes de espera requeridos foi feita uma análise conjunta das duas condições de projeto.
\end{abstract}

Palavras-chave: volumes de espera, segurança das barragens, modelo chuva-vazão.

\section{INTRODUÇÃO}

Neste trabalho são descritos os estudos hidrológicos necessários para a avaliação dos volumes de espera dos aproveitamentos do Sistema Produtor de Água Cantareira, maior sistema de abastecimento da Região Metropolitana de São Paulo (RMSP). Cabe destacar que estes estudos fazem parte de alguns dos condicionantes estabelecidos pelo Departamento de Águas e Energia do Estado de São Paulo (DAEE) na outorga do Sistema Cantareira.

O sistema Cantareira resume-se na transposição das águas do Alto rio Piracicaba para a bacia do Alto rio Tietê, representando o principal manancial de abastecimento da RMSP, tanto em termos de quantidade como de qualidade. Esta transposição é composta pelos reservatórios de Jaguari-Jacareí,
Cachoeira, Atibainha e Juqueri (Paiva Castro), interligados através de túneis e canais, que deságuam no reservatório de Águas Claras para alimentar a ETA Guaraú e, então, ser distribuída para a Grande São Paulo. etapas:

Os estudos realizados incluíram as seguintes

- Análise da disponibilidade de dados;

- Determinação das características fisiográficas na área de abrangência do Sistema Cantareira;

- Análise de freqüência de chuvas máximas de 1 dia;

- Análise metodológica e definição dos critérios de projeto;

* Esta é uma publicação póstuma do eng. Luis Antonio Villaça de Garcia, falecido precocemente em 02/12/2010, quando o artigo já havia sido submetido à RBRH. Os coautores procederam às alterações solicitadas pelos revisores, mas a essência do artigo continua sendo de autoria do primeiro autor. A carreira do colega Luis foi caracterizada pela competência técnica, pela seriedade e pelo extremo rigor profissional. Esta publicação é uma simples homenagem a sua memória - os Coautores. 
- Determinação das tormentas de projeto;

- Determinação dos hidrogramas de projeto;

- Análise da segurança hidrológica das barragens;

- Avaliação dos volumes de espera.

\section{DISPONIBILIDADE DE DADOS}

\section{Dados Pluviométricos}

Foram utilizados os dados pluviométricos das estações da Agência Nacional de Águas (ANA), do Departamento de Águas e Energia do Estado de São Paulo (DAEE), da SABESP e da Empresa Metropolitana de Águas e Energia S. A. (EMAE). Foram selecionados 48 postos pluviométricos baseando-se nos seguintes critérios:

- Inicialmente foi feita uma análise das extensões das séries de precipitações máximas de 1 dia dos postos pluviométricos. As séries de precipitações máximas de 1 dia com extensão inferior a 15 anos foram descartadas devido à pouca representatividade estatística para os objetivos deste estudo;

- Complementarmente foi feita uma análise da representatividade do regime pluvial dos postos pluviométricos pré-selecionados. Esta análise considerou a posição geográfica em relação às sub-bacias dos rios Jaguari, Jacareí, Cachoeira, Atibainha e Juqueri. Para isso foram utilizados os mapas das sub-bacias com a localização dos postos pluviométricos considerando uma faixa de $10 \mathrm{~km}$ no entorno.

\section{Dados Cartográficos}

$\mathrm{Na}$ área de abrangência dos estudos, ou seja, as bacias dos rios Jaguari, Cachoeira, Atibainha e Juqueri nos aproveitamentos do Sistema Cantareira foram utilizadas as bases cartográficas na escala 1:50.000, com eqüidistância das curvas de nível de $20 \mathrm{~m}$, elaboradas pelo Instituto Brasileiro de Geografia e Estatística e Instituto Geográfico e Cartográfico - IBGE.

\section{Dados Geológicos}

Os dados geológicos utilizados neste trabalho e necessários para a caracterização hidrogeológica das bacias do Sistema Cantareira foram:
- Mapa Geológico do Estado de São Paulo versão 2.0, escala 1:750.000 - CPRM - Serviço Geológico do Brasil;

- Mapa Geológico do Estado de Minas Gerais, escala 1:1.000.000 - CPRM - Serviço Geológico do Brasil.

\section{Dados de Uso e Ocupação do Solo}

Os dados de uso e ocupação do solo na área de abrangência das bacias do Sistema Cantareira foram obtidos junto a SABESP. A classificação do uso e ocupação do solo foi obtida através de interpretação da imagem de satélite LandSat 7 ETM para os anos de 1989, 1999 e 2003 elaborada pelo ISA Instituto Socioambiental.

\section{Dados Operacionais dos Aproveitamentos}

Foram utilizadas as relações cota x área x volume dos reservatórios obtidas em levantamento recente contratado pela SABESP (Azimute, 2008). As relações cota $\mathrm{x}$ descarga dos vertedouros e os NA operacionais foram obtidos do DATA OPER Sistema Cantareira (1991).

\section{CARACTERÍSTICAS FISIOGRÁFICAS DAS BACIAS HIDROGRÁFICAS}

O Sistema Cantareira é formado pelas bacias dos rios Jaguari/Jacareí, Cachoeira, Atibainha e Juqueri nos aproveitamentos. A área total é de 2.303 $\mathrm{km}^{2}$, sendo $56 \%$ no Estado de São Paulo e $44 \%$ no Estado de Minas Gerais. As características fisiográficas levantadas na área de abrangência das bacias são:

- áreas de drenagem e tempo de concentração nas bacias e sub-bacias;

- Caracterização do uso e ocupação do solo;

- Classificação hidrogeológica do solo;

- Determinação do Número da Curva CN.

\section{Delimitação das sub-bacias hidrográficas}

As bacias dos rios Jaguari/Jacareí, Cachoeira, Atibainha e Juqueri nos aproveitamentos foram subdivididas em função da necessidade de uma análise geológica mais abrangente e da representatividade do modelo chuva-vazão. A integração computacional das bacias hidrográficas permitiu determinar as áreas de drenagem. A Figura 1 apresenta as 


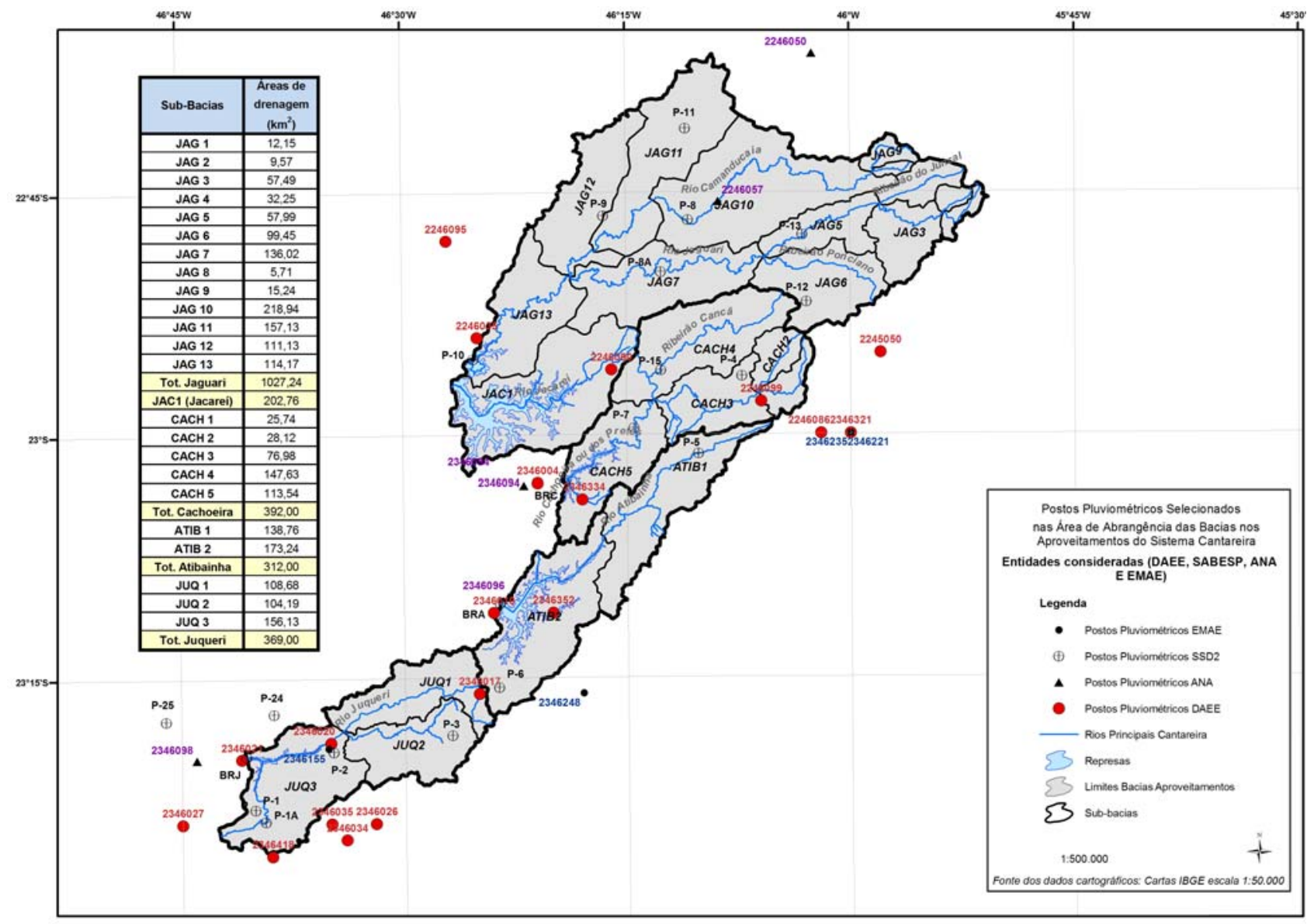

Figura 1 - Sub-bacias Hidrográficas e postos pluviométricos

sub-bacias hidrográficas, a rede hídrica principal, as áreas de drenagem das sub-bacias e os postos pluviométricos selecionados.

\section{Determinação dos perfis longitudinais dos talvegues das bacias}

Foram levantados os perfis longitudinais dos talvegues das bacias hidrográficas dos rios Jaguari, Jacareí, Cachoeira, Atibainha e Juqueri.

\section{Determinação do tempo de concentração nas bacias e sub-bacias}

A área de abrangência dos estudos é predominantemente rural. Sendo assim o tempo de concentração foi determinado utilizando-se a equação do Corps of Engineers determinada e testada em bacias rurais (Silveira, 2005). A fórmula é apresentada pela seguinte equação:
$\mathrm{Tc}=0,191 \mathrm{~L}^{0,76} \mathrm{~S}^{-0,19}$

Onde:

Tc= tempo de concentração, em horas;

$\mathrm{L}=$ comprimento do talvegue da bacia hidrográfica, em km;

$\mathrm{S}=$ declividade entre a cota de montante e jusante, $\mathrm{em} \mathrm{m} / \mathrm{m}$

\section{Caracterização do uso e ocupação do solo}

Os dados de uso e ocupação dos solos na área de abrangência dos estudos foram obtidos da classificação realizada pelo ISA - Instituto Socioambiental (Whately, 2007). A caracterização do uso e ocupação do solo é necessária para que, juntamente com a análise geológica da área de abrangência, seja possível determinar as condições de permeabilidade do solo, ou da capacidade de infiltração, parâmetro importante na modelagem de transformação chuvavazão. 
Para a finalidade deste trabalho foi realizada uma síntese da caracterização do uso e ocupação do solo por sub-bacias, utilizando-se para isso os recursos de geoprocessamento. Há uma predominância na região de campos antrópicos e vegetação.

\section{Classificação hidrogeológica do solo}

As condições de escoamento superficial e de infiltração numa bacia hidrográfica dependem, além dos gradientes topográficos, do grau de uso e ocupação da área e da natureza dos solos constituintes, se mais ou menos percoláveis.

Para se proceder à quantificação de um parâmetro que retrate tal propriedade num determinado solo dispõe-se da classificação dos grupos hidrológicos de solos do SCS - Soil Conservation Service (1951). Conjugando-se esta classificação com a tipologia de solos apresentada no trabalho desenvolvido por Setzer \& Porto (1979) e, posteriormente, por Kutner et al. (2001), há condições para se adaptar adequadamente o sistema classificatório do SCS aos solos ocorrentes em climas tropicais, onde os processos de intemperismo das rochas diferem radicalmente, daqueles do hemisfério norte, por sua natureza, intensidade e amplitude.

Para a caracterização pedológica das bacias hidrográficas que abastecem o Sistema Cantareira procedeu-se à análise geológica da área a fim de se identificar e mapear os principais litotipos ocorrentes e, portanto dos solos texturalmente mais significativos, resultantes diretos que são dos processos de intemperismo que atuam sobre as rochas. As bacias hidrográficas contribuintes do Sistema Cantareira, abrangendo as bacias integrais dos rios Jaguari, Atibainha, Cachoeira e o trecho superior da bacia do rio Juqueri foram compartimentados em sub-bacias tendo-se procedido à identificação dos litotipos constituintes.

Quanto aos litotipos constituintes, que implica na avaliação da composição pedológica textural dos solos das bacias hidrográficas contribuintes aos reservatórios do Sistema Cantareira, a análise realizada revelou a presença de uma grande variedade de espécies rochosas. A área de estudo é considerada extremamente complexa sob o ponto de vista geológico, pois resultou da ação de sucessivos e intensos processos orogênicos relacionados com processos da escala de colisões crustais. A área possui diversas entidades tectono-estratigráficas, em sua maioria datadas do Proterozóico Superior, ou Neoproterozóico, sendo entretanto dominada pelo chamado Nappe Socorro-Guaxupé, feição estrutural muito complexa que consiste de um imenso dobra- mento semi-horizontal, de amplitude quilométrica. Com tal deformação, de âmbito regional, a seqüência estratigráfica destas rochas foi totalmente alterada, fato este que por si só seria irrelevante para os objetivos do presente estudo. Ressalta-se por outro lado que a grande variabilidade dos litotipos existentes é uma das principais conseqüências da ação daqueles processos geológicos tão intensos.

Mencionam-se os diversos magmatismos ocorridos na área (geração de rochas ígneas), assim como os inúmeros tipos de rochas metamórficas ali ocorrentes em conseqüência dos variados graus de metamorfismo a que as rochas então presentes foram submetidas durante o processo. Outro efeito é a grande deformação, por dobramentos e por cisalhamentos, que os maciços rochosos apresentam. Como conseqüência direta, o elevado grau de descontinuidades dos maciços interfere diretamente na intensidade do intemperismo a que essas rochas são submetidas, gerando solos mais espessos e mais desenvolvidos.

A fim de ilustrar a grande diversidade litológica da área, apresenta-se na Tabela 1 a relação dos litotipos constituintes da área de estudo, abrangendo o Estado de São Paulo. Na última coluna "Grupos Litológicos" menciona-se a classificação a ser adotada neste trabalho reunindo litologias de solos afins.

Para fins de uniformização foram utilizados os mapeamentos geológicos executados pela CPRM em ambos os Estados, respectivamente em escalas 1:750.000 e 1:1.000.000, o que garantiu maior uniformidade, tanto das classificações litológicas, como das nomenclaturas geológicas adotadas em ambas as áreas. A Figura 2 apresenta o mapa geológico na área de abrangência dos estudos.

A fim de permitir a análise proposta, esse conjunto de rochas foi dividido em grupos com o objetivo de tipificar os solos deles decorrentes para assim melhor avaliá-los quanto ao comportamento hidráulico-hidrológico das bacias hidrográficas.

Apresentam-se a seguir os Grupos em que o conjunto dos litotipos ocorrentes foi subdividido; considera-se que tais grupos representem os litotipos mais significativos sob o ponto de vista do comportamento hidráulico-hidrológico de seus solos:

- Grupo 1 - Englobando rochas designadas genericamente como Granitóides, em grande parte pertencentes ao Orógeno SocorroGuaxupé, sendo representadas principalmente por granitos, adamelitos, sienitos, tonalitos e charnockitos; 
Tabela 1 - Ocorrências Litológicas nas Bacias Hidrográficas do Sistema Cantareira - na porção do Estado de São Paulo

\begin{tabular}{|c|c|c|c|c|c|}
\hline \begin{tabular}{|c} 
Codificação no \\
Mapa \\
Geológico \\
\end{tabular} & Litotipos Característicos & $\begin{array}{c}\text { Unidade/ De si gnação } \\
\text { Petrográfica }\end{array}$ & Evento/Grupo/Complexo & Idade & $\begin{array}{c}\text { Grupo } \\
\text { Litológico }\end{array}$ \\
\hline NP3pg_2mi & Granitói des foliados calcoalcalinos & Morro Azul - Igaratá & Orógeno Paranapiacaba & NPr zoi co & 1 \\
\hline NP3pg_2sl & Granitói des foliados & Granito Sa. do Lopo & \multirow{5}{*}{$\begin{array}{l}\text { Posicionam. } \\
\text { Estratigráf. } \\
\text { Impreciso }\end{array}$} & \multirow{5}{*}{ NPrzoico } & \multirow{5}{*}{1} \\
\hline NP3pg_2ju & Granitói des foliados & GranitoJundiuvira & & & \\
\hline NP3pg_2mc & Granitóides foliados indiferenciados & Morro Claro / Imbiruçu & & & \\
\hline NP3pg_2pa & Granitóides foliados indiferenciados & Granito Pau Pedra & & & \\
\hline NP3pg_2Stb & Granitói des foliados & Granito Terra Boa & & & \\
\hline NP3sg 3Apc & Granitoides & Granito Piracaia & \multirow{17}{*}{$\begin{array}{l}\text { Orógeno } \\
\text { Socorro - Guaxupé }\end{array}$} & \multirow{17}{*}{ NPrzoico } & \multirow{17}{*}{1} \\
\hline NP3sg_3Ast & Granitoides & Granito Atibaia & & & \\
\hline NP3sg_2bv & Granitos foliados pe ralcalinos & Granito Sa. Boa Vista & & & \\
\hline NP3sg_2Cfx & Granitoi des & S. Francisco Xavier & & & \\
\hline NP3sg_2lpe & Granitoides & Gran. Pedra Branca & & & \\
\hline NP3sg_2Ssi & Granitoi des & Gran. Sa. dos Índios & & & \\
\hline NP3sg_1lbb & Granitói des fol iados calcialcalinos & Granitóides Sa. Do Barro & & & \\
\hline NP3sg_1lbp & Granitói des foliados & Suíte Brag. Paulista & & & \\
\hline NP3sg_1lcr & Granitói des foliados & Granito Cantareira & & & \\
\hline NP3sg_1lma & Granitói des foliados & Granito Mairiporã & & & \\
\hline NP3sg_1lmp & Granitói des foliados & Granito Mo.do Pão & & & \\
\hline \begin{tabular}{|l|} 
NP3sg_1lmt \\
\end{tabular} & Granitói des foliados & Granito Mato Mole & & & \\
\hline NP3sg_1lsp & Granitói des foliados & Granito Sa. Preta & & & \\
\hline NP3sg_1Sgo & Granitói des fol iados & Granito Gonçalves & & & \\
\hline NP3sg_1Snp & Granitói des foliados & Granito Nazaré Paulista & & & \\
\hline NP3sg_1Sqc & Granitói des fol iados peraluminosos & Quatro Cantos & & & \\
\hline NP3sg_1Stt & Granitói des foliados & Tico-Tico & & & \\
\hline NP3srbt & Me tapelitos e anfibolitos & Fm. Boturuna & \multirow[b]{2}{*}{ Grupo São Roque } & \multirow[b]{2}{*}{ NPrzoico } & \multirow[b]{2}{*}{2} \\
\hline NP3srer & Filitos, anfibolitos e Metarenitos finos & Fm. Estrada dos Romeiros & & & \\
\hline NPvm & $\begin{array}{l}\text { Paragnaisse s } \\
\text { migmatizados }\end{array}$ & $\begin{array}{c}\text { Unid. Paragnais. } \\
\text { migmatít. Superior }\end{array}$ & \multirow{2}{*}{$\begin{array}{l}\text { Complexo Varginha / } \\
\text { Guaxupé }\end{array}$} & \multirow[b]{2}{*}{ NPrzoico } & \multirow[b]{2}{*}{3} \\
\hline NPvog & Ortognaisses Migmatíticos & $\begin{array}{l}\text { Uni dade Ortoganais. } \\
\text { migmatíticos }\end{array}$ & & & \\
\hline MP2si & Micaxistos, Metapelitos e Quartzitos & & Grupo Sa. do Itaberaba & MsPrzoico & 4 \\
\hline
\end{tabular}

Fonte: Mapa Geológico do Estado de São Paulo - CPRM - v 2.0- Esc. 1:750.000-2006

- Grupo 2 - Primariamente representado pelos filitos, metapelitos e metarritmitos do Grupo São Roque. Há também outros litotipos minoritários;

- Grupo 3 - Reúne primariamente os gnaisses e migmatitos do Complexo Varginha- Guaxupé;

- Grupo 4 - Grupo muito heterogêneo, datado do Mesoproterozoico, mais antigo, geologicamente denominado Gpo. Serra do Itaberaba, abrangendo primariamente micaxistos, podendo também apresentar afloramentos de anfibolitos, metandesitos, quartzitos, extrusivas metamorfisadas etc.

Uma vez identificados quatro grupos englobando os principais litotipos presentes quantificouse, em cada uma das sub-bacias acima definidas, suas ocorrências em termos de áreas territoriais ocupadas e nas percentagens de ocorrência de cada um desses grupos de litotipos em cada sub-bacia.

Apresenta-se na Figura 3 que abrange a área de estudo, além das diversas sub-bacias em que a área foi dividida, uma síntese geológica destacandose as áreas de ocorrência dos Grupos Litológicos Tipo geradores dos solos mais significativos sob o ponto de vista hidrológico.

Neste ponto é fundamental assinalar que cada um destes litotipos gera, através dos processos de intemperismo atuantes, mantos de solos texturalmente muito variáveis, desde os mais arenosos (mais permeáveis e percoláveis), até os argilosos (menos permeáveis e, portanto, com maiores índices de escoamento superficial); entre estes dois extremos há toda uma gama de solos decorrentes da miscigenação destas texturas extremas.

Conforme já mencionado, a caracterização e a quantificação do comportamento hidráulico dos solos pode ser feita por meio de sistemas de classifi- 


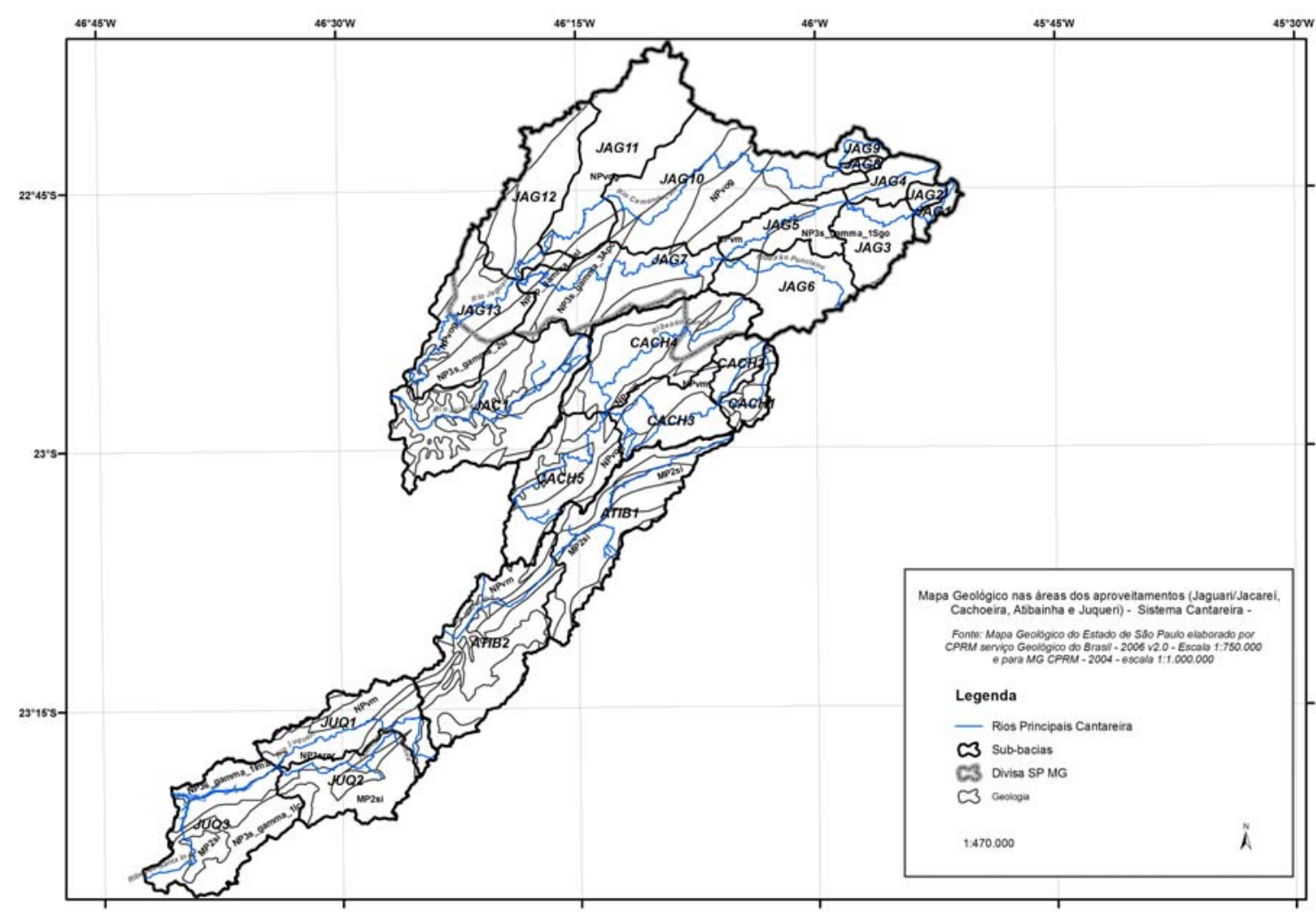

Figura 2 - Geologia na Área de Abrangência do Sistema Cantareira - Grupos de Solos Ocorrentes

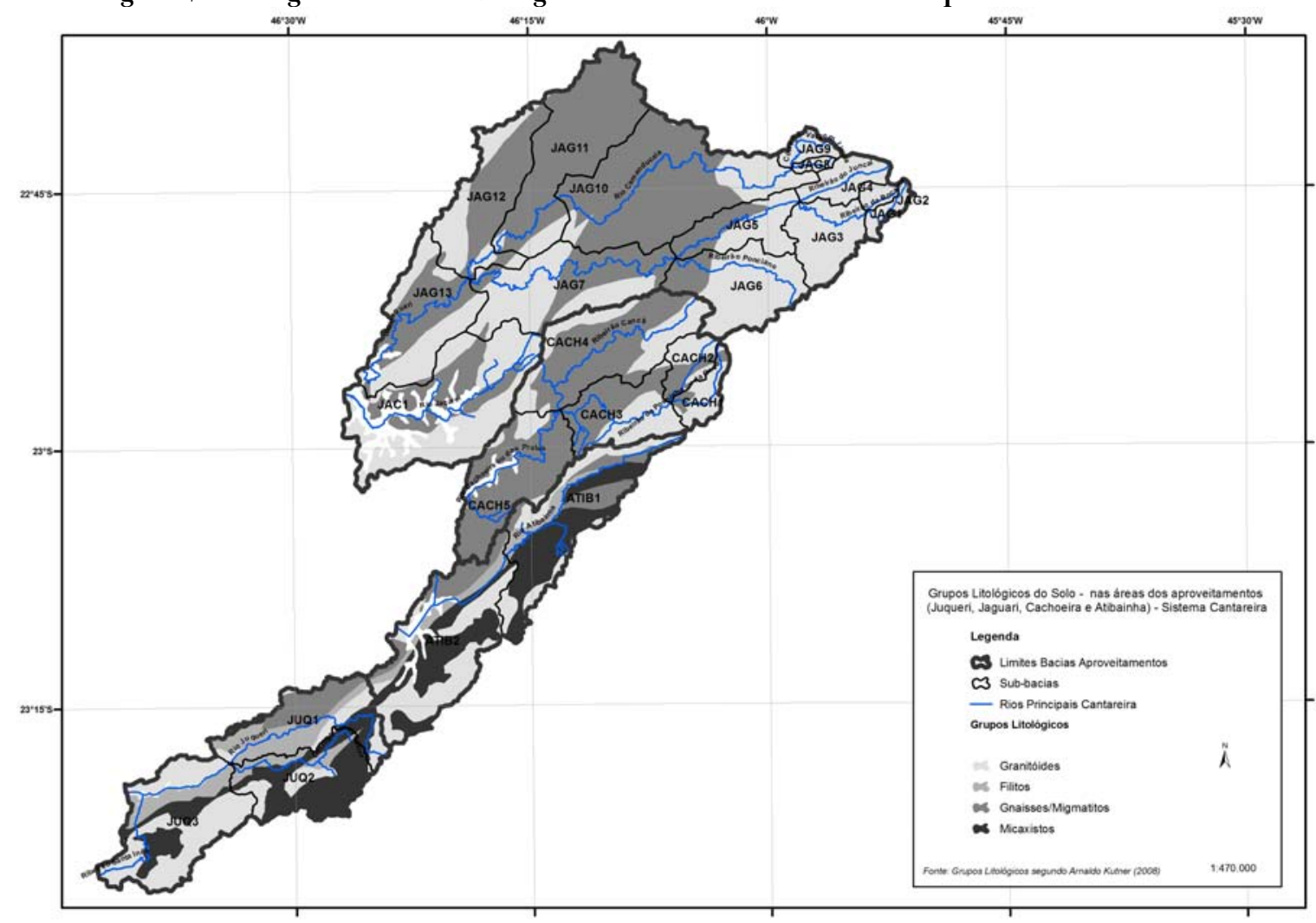

Figura 3 - Grupos Litológicos - Tipo ocorrentes na Área de Abrangência do Sistema Cantareira 
cação específicos. Dois destes sistemas destacam-se por suas abrangências: o do "Soil Conservation Service” - SCS (1951) e o de Setzer e Porto (1979).

O sistema de classificação do SCS divide os solos em 4 Grupos Hidrológicos: esta classificação utiliza como principal critério a composição textural dos solos e oferece, como grande vantagem, boa abrangência e aplicabilidade em relação aos tipos de cobertura e usos do solo, aliás da forma tradicional como comumente são feitos, em virtude da maior disponibilidade destes dados. O sistema de classificação elaborado por Setzer e Porto (1979), tomando por base algumas das características pedológicas mais marcantes comumente apresentadas pelos solos em climas tropicais, classifica-os em 5 Grupos Hidrológicos. Por se referir ao nosso meio físicoquímico é melhor correlacionável com os litotipos ocorrentes na área de interesse. Kutner et al (2001) adotou a combinação de ambas as classificações, visando maior abrangência do método de estudo então proposto.

O fato já destacado de que cada litotipo gera um solo típico e característico, principalmente quanto à sua textura, tendo em vista as peculiaridades mineralógicas de cada um destes litotipos e o processo de intemperismo atuante, implica também no fato que os solos de cada litotipo consistam de misturas dos solos dos diversos Grupos Hidrológicos mencionados nos Sistemas Classificatórios. Em outros termos: o solo de cada litotipo é, a rigor, constituído pela mistura dos vários Grupos Hidrológicos de Solos. Adotando-se os critérios de Classificação Hidrológica dos Solos de Setzer e Porto (1979), do SCS e de Kutner et.al, (2001) pode-se compor a Tabela 2, o qual apresenta as participações percentuais dos vários grupos hidrológicos de solos para cada um dos diferentes litotipos ocorrentes nas bacias do Sistema Cantareira.

Tabela 2 - Composição Porcentual Proposta

\begin{tabular}{|l|c|c|c|c|}
\hline \multirow{2}{*}{ GRUPO UTOLÓGICO } & \multicolumn{4}{|c|}{ GRUPOS HIDROLÓGICOS DE } \\
\cline { 2 - 5 } & A & B & C & D \\
\hline 1- Grupo das rochas Granitoides & 15 & 45 & 15 & 25 \\
\hline 2- Grupo dos Filitos & 0 & 0 & 50 & 50 \\
\hline 3- Grupo dos Gnaisses e Migmatitos & 15 & 35 & 25 & 25 \\
\hline 4- Grupo dos Micaxistos & 5 & 10 & 35 & 50 \\
\hline
\end{tabular}

É importante assinalar que, dada a extrema variabilidade dos litotipos constituintes num mesmo Grupo Litológico, como é o caso da área de interesse no presente estudo, poderá vir a ser necessária uma reavaliação da distribuição percentual dos
Grupos Hidrológicos de Solos que compõem cada um destes litotipos, remetendo portanto a um eventual processo de re-calibragem.

\section{Litotipos e Grupos Hidrológicos de Solos Ocorrentes na Bacia do Sistema Cantareira}

Apresentam-se na Tabela 4 as participações percentuais de cada Grupo Litológico - Tipo em cada uma das sub-bacias, relativamente à área total desta sub-bacia. De posse também da constituição percentual dos diversos Grupos Hidrológicos de Solos por Grupo Litológico-Tabela 2 calculou-se para cada sub-bacia a participação percentual que cada Grupo Hidrológico de Solo tem nessa subbacia. Cabe observar que nas sub-bacias que contém as represas Jaguari (JAG13), Jacareí (JAC1), Cachoeira (CACH5), Atibainha (ATIB2), Cascata (JUQ1) e Paiva Castro (JUQ3) foram descontadas as áreas dos reservatórios, obtendo-se os grupos hidrológicos apenas da área de solos.

\section{Determinação do CN (Número da Curva)}

Um dos parâmetros mais importantes no processo de transformação chuva-vazão, o denominado número da curva $\mathrm{CN}$; conforme conceituado pelo método do USSCS - U. S. Soil Conservation Service, retrata as condições de escoamento superficial e de infiltração ocorrentes nos solos das bacias hidrográficas.

Tabela 3 - Valores de CN em função do uso e ocupação do solo

\begin{tabular}{|l|c|c|c|c|}
\hline \multirow{2}{*}{ Usos e Ocupação } & \multicolumn{4}{|c|}{ CN por grupo hidr dógico de solo } \\
\cline { 2 - 5 } & A & B & C & D \\
\hline Afloramento rochoso & 98 & 98 & 98 & 98 \\
\hline Agricultura & 39 & 61 & 74 & 80 \\
\hline Campo Antrópico & 57 & 73 & 82 & 86 \\
\hline Campo de Altitude & 57 & 73 & 82 & 86 \\
\hline Campo cerr ado & 57 & 73 & 82 & 86 \\
\hline Lazer & 39 & 61 & 74 & 80 \\
\hline Indústria & 81 & 88 & 91 & 93 \\
\hline Mineração & 98 & 98 & 98 & 98 \\
\hline Ocupação Dispersa & 57 & 72 & 81 & 86 \\
\hline Ocupação Urbana de Alta Densidade & 77 & 85 & 90 & 92 \\
\hline Ocupação Urbana de Média Densidade & 61 & 75 & 83 & 87 \\
\hline Reflor estamento & 39 & 61 & 74 & 80 \\
\hline Solo exposto & 77 & 86 & 91 & 94 \\
\hline $\begin{array}{l}\text { Vegetação Secundária em estágio } \\
\text { avançado de regeneração ou primária }\end{array}$ & 30 & 48 & 65 & 73 \\
\hline $\begin{array}{l}\text { Vegetação Secundária em estágio médio ou } \\
\text { inicial de regeneração }\end{array}$ & 48 & 67 & 77 & 83 \\
\hline
\end{tabular}


Tabela 4 - Resumo das características fisiográficas determinadas nas bacias e sub-bacias da área de abrangência

\begin{tabular}{|c|c|c|c|c|c|c|c|c|c|c|c|c|c|c|}
\hline \multirow{2}{*}{ SubBacias } & \multirow{2}{*}{$\begin{array}{c}\text { Áreas de } \\
\text { drena gem } \\
\left(\mathrm{km}^{2}\right) \\
\end{array}$} & \multirow{2}{*}{$\begin{array}{c}\text { Cota } \\
\text { de montante } \\
(\mathrm{m}) \\
\end{array}$} & \multirow{2}{*}{\begin{tabular}{|c|} 
Cota \\
dejusinte \\
$(\mathrm{m})$
\end{tabular}} & \multirow{2}{*}{\begin{tabular}{|c|}
$\begin{array}{c}\text { Comprimento } \\
\text { do talvegue } \\
(\mathrm{km})\end{array}$
\end{tabular}} & \multirow{2}{*}{$\begin{array}{c}\text { Tempode } \\
\text { concentraçáo } \\
\text { (h) }\end{array}$} & \multirow{2}{*}{\begin{tabular}{|c|} 
Tempode \\
retardo \\
(min)
\end{tabular}} & \multicolumn{4}{|c|}{$\begin{array}{l}\text { PEREENTAGENS DOS GRUPOS HIDROĹOGICOS } \\
\text { DE SOLOS POR SUB-BACIA HIDROGRÁFCA }\end{array}$} & \multirow{2}{*}{$\begin{array}{c}\text { Uso e } \\
\text { Ouupação } \\
\text { Predominante }\end{array}$} & \multirow[t]{2}{*}{$\mathbf{O N}^{(1)}$} & \multirow[t]{2}{*}{$\mathbf{C N}^{(2)}$} & \multirow[t]{2}{*}{ SubBacias } \\
\hline & & & & & & & $\bar{A}$ & B & $\mathrm{C}$ & D & & & & \\
\hline JAG 1 & 12,15 & 1830,0 & 1487,5 & 8,3 & 1,7 & 62,9 & 15,0 & 45,0 & 15,0 & 25,0 & Rural & 62 & 62 & JAG 1 \\
\hline JAG 2 & 9,57 & 1860,0 & 1487,5 & 4,8 & 1,0 & 37 & 15,0 & 45,0 & 15,0 & 25,0 & Rural & 62 & 62 & JAG 2 \\
\hline JAG 3 & 57,49 & 1915,0 & 1417,4 & 18,5 & 3,5 & 125 & 15,0 & 45,0 & 15,0 & 25,0 & Rural & 63 & 63 & JAG 3 \\
\hline JAG 4 & 32,25 & 1785,0 & 1417,4 & 12,7 & 2,6 & 93 & 15,0 & 45,0 & 15,0 & 25,0 & Rural & 65 & 65 & JAG 4 \\
\hline JAG 5 & 57,99 & 1670,0 & 1272,0 & 21,7 & 4,2 & 152 & 15,0 & 40,8 & 19,2 & 25,0 & Rural & 70 & 70 & JAG 5 \\
\hline JAG 6 & 99,45 & 1780,0 & 1272,0 & 20,9 & 3,9 & 140 & 15,0 & 43,0 & 17,0 & 25,0 & Rural & 65 & 65 & JAG 6 \\
\hline JAG 7 & 136,02 & 1620,0 & 906,0 & 47,1 & 7,9 & 285 & 15,0 & 40,9 & 19,1 & 25,0 & Rural & 73 & 73 & JAG 7 \\
\hline JAG 8 & 5,71 & 1900,0 & 1513,0 & 5,3 & 1,1 & 40 & 15,0 & 45,0 & 15,0 & 25,0 & Rural & 65 & 65 & JAG 8 \\
\hline JAG 9 & 15,24 & 1875,0 & 1513,0 & 9,1 & 1,9 & 68 & 15,0 & 45,0 & 15,0 & 25,0 & Rural & 70 & 70 & JAG 9 \\
\hline JAG 10 & 218,94 & 1750,0 & 926,0 & 48,5 & 7,9 & 285 & 15,0 & 36,9 & 23,1 & 25,0 & Rural & 73 & 73 & JAG 10 \\
\hline JAG 11 & 157,13 & 1490,0 & 920,0 & 40,0 & 7,1 & 254 & 15,0 & 35,8 & 24,2 & 25,0 & Rural & 73 & 73 & JAG 11 \\
\hline JAG 12 & 111,13 & 1480,0 & 906,0 & 31,2 & 5,6 & 201 & 15,0 & 39,1 & 20,8 & 25,0 & Rural & 74 & 74 & JAG 12 \\
\hline JAG 13 & 114,17 & 1355,0 & 798,0 & 37,7 & 6,7 & 241 & 15,0 & 40,3 & 19,7 & 25,0 & Rural & 72 & 69 & JAG 13 \\
\hline JAGUARI & 1027,24 & 1830,0 & 798,0 & 121,8 & 18,2 & 655 & & & & & Rural & 71 & 71 & JAGUARI \\
\hline JACl (JACAREÍ) & 202,76 & 1340,0 & 795,0 & 36,1 & 6,5 & 233 & 15,0 & 41,9 & 18,1 & 25,0 & Rural & 68 & 61 & JACI (JACAREÍ) \\
\hline $\mathrm{CACH} 1$ & 25,74 & 1830,0 & 1178,5 & 12,2 & 2,2 & 80 & 15,0 & 43,1 & 16,9 & 25,0 & Rural & 64 & 64 & CAOH 1 \\
\hline $\mathrm{CACH} 2$ & 28,12 & 1770,0 & 1178,5 & 11,5 & 2,1 & 77 & 15,0 & 41,0 & 18,9 & 24,9 & Rural & 62 & 62 & CAOH 2 \\
\hline $\mathrm{CACH} 3$ & 76,98 & 1485,0 & 875,0 & 22,2 & 4,0 & 144 & 15,0 & 39,5 & 20,4 & 25,0 & Rural & 72 & 72 & CAOH 3 \\
\hline $\mathrm{CACH} 4$ & 147,63 & 1558,0 & 875,0 & 31,6 & 5,5 & 196 & 15,0 & 38,4 & 21,5 & 25,0 & Rural & 71 & 71 & CAOH 4 \\
\hline CACH 5 & 113,54 & 870,0 & 820,0 & 23,2 & 6,7 & 241 & 15,0 & 36,0 & 24,0 & 25,0 & Rural & 70 & 68 & CACH 5 \\
\hline CACHOEIRA & 392,00 & 1830,0 & 820,0 & 55,0 & 8,6 & 309 & & & & & Rural & 70 & 69 & CACHOEIRA \\
\hline ATIB 1 & 138,76 & 1335,0 & 795,0 & 30,8 & 5,6 & 201 & 9,2 & 23,4 & 29,0 & 38,3 & Rural & 74 & 74 & ATIB1 \\
\hline ATIB 2 & 173,24 & 1000,0 & 778,0 & 17,5 & 3,9 & 139 & 10,2 & 27,1 & 26,8 & 35,9 & Rural & 70 & 66 & ATIB 2 \\
\hline ATIBAINHA & 312,00 & 1335,0 & 778,0 & 48,3 & 8,5 & 306 & & & & & Rural & 72 & 70 & ATIBAINHA \\
\hline JUQ 1 & 108,68 & 1390,0 & 747,0 & 28,0 & 4,9 & 177 & 8,2 & 21,1 & 33,4 & 37,3 & Rural & 72 & 72 & JUQ1 \\
\hline JUQ 2 & 104,19 & 1055,0 & 747,0 & 23,2 & 4,7 & 170 & 5,9 & 14,4 & 34,0 & 45,6 & Rural & 74 & 74 & JUQ2 \\
\hline JUQ3 & 156,13 & 1050,0 & 741,0 & 19,6 & 4,0 & 145 & 10,7 & 31,1 & 24,3 & 33,9 & Rural & 71 & 70 & JUQ3 \\
\hline JUQUERI & 369,00 & 1390,0 & 741,0 & 40,6 & 7,0 & 252 & & & & & Rural & 72 & 72 & JUQUERI \\
\hline
\end{tabular}

CN foi calculado considerando-se as áreas inundadas da represa, conforme tabela abaixo

\begin{tabular}{|l|l|c|c|c|}
\hline Re presa & Sub-bacia & NA máx op & Área $\left(\mathrm{km}^{2}\right)$ & fração da Atot \\
\hline Jaguari & JAG13 & 844,00 & 11,76 & 0,10 \\
\hline Jacareí & JAC1 & 844,00 & 37,98 & 0,19 \\
\hline Cachoeira & CACH5 & 821,78 & 8,59 & 0,08 \\
\hline Atibainha & ATIB2 & 786,86 & 21,99 & 0,13 \\
\hline Juque ri & JUQ3 & 745,61 & 4,64 & 0,03 \\
\hline
\end{tabular}

Áreas das represas foram obtidas do relatório Azimute - REL - 15607-07B

(2) CN foi calculado desconsiderando-se as áreas das represas. Foi considerada apenas a parte do solo.

Em função dos principais usos encontrados nas sub-bacias, fez-se uma associação destes usos aos valores de $\mathrm{CN}$ encontrados na literatura (Hydrology Handbook, 1996). A Tabela 3 apresenta os valores de CN por uso e ocupação.

Os valores de CN para cada sub-bacia foram determinados utilizando-se o seguinte procedimento:

- Determinou-se para cada sub-bacia as porcentagens de uso e ocupação do solo em relação a sua área, utilizando-se para isso as ferramentas de geoprocessamento;

- Cada uso encontrado na sub-bacia foi associado ao respectivo grupo hidrológico de solo apresentado na Tabela 2 e aos correspondentes valores de $\mathrm{CN}$ apresentados na Tabela 3. Isto permitiu determinar o valor de CN por uso e ocupação;
- o CN total da sub-bacia foi obtido pela soma dos produtos entre os valores de CN para cada uso e ocupação e a respectiva porcentagens da sua área total.

\section{Resumo das Características Fisiográficas}

A Tabela 4 apresenta um resumo das características fisiográficas determinadas nas bacias e subbacias dos rios Jaguari, Cachoeira, Atibainha e Juqueri nos aproveitamentos do Sistema Cantareira. A tabela apresenta os seguintes elementos:

- Identificação dos códigos atribuídos para cada sub-bacia. Em destaque estão as bacias totalizadas;

- Áreas de drenagem, em km²;

- Cota de montante, em metros;

- Cota de jusante, em metros;

- Comprimento do talvegue, em km; 
- Tempo de concentração, em horas;

- Tempo de retardo, em minutos;

- Porcentagens dos grupos hidrológicos de solo (A, B, C e D) determinadas para cada sub-bacia;

- Uso e ocupação predominante;

- Valor de CN obtido considerando-se as áreas inundadas pelas represas. Neste caso o valor de $\mathrm{CN}$ adotado para estas áreas foi igual a 98 ;

- Valor de $\mathrm{CN}$ obtido considerando-se apenas as áreas de solos.

\section{ANÁLISE DE FREQÜÊNCIA DE CHUVAS MÁXIMAS}

\section{Séries de Chuvas Máximas de 1 Dia}

As séries de precipitações máximas de 1 dia dos postos pluviométricos pré-selecionados foram determinadas através da identificação da máxima altura pluviométrica das séries de totais precipitados diários em cada ano hidrológico, com início em outubro de um ano e fim em setembro do ano subseqüente. As precipitações máximas de 1 dia foram desconsideradas nos anos hidrológicos com falhas de observação no semestre chuvoso que cobre o período de outubro a março.

Inicialmente foi feita uma análise das extensões das séries de precipitações máximas de 1 dia dos postos pluviométricos. Aplicados os critérios descritos anteriormente foram selecionados 48 postos pluviométricos. As séries de precipitações máximas de 1 dia foram verificadas quanto à presença de "outliers" ou valores extraordinários através da metodologia Grubbs \& Beck (1972), recomendada pelo United States Water Resources Council. Foram identificados alguns "outliers" que, conforme recomendado, foram retirados das séries.

Para as séries de precipitações máximas anuais de 1 dia nos 48 postos pluviométricos selecionados foram obtidos os principais parâmetros estatísticos como o número de elementos, a média, o mínimo, o máximo, o desvio-padrão e os coeficientes de assimetria e curtose. Os coeficientes de assimetria e curtose revelaram as distribuições probabilísticas mais adequadas para representar as séries de precipitações máximas anuais de 1 dia.

Os coeficientes de assimetria estão situados entre $-0,3$ e 1,3 , com uma média ponderada pela extensão da série de 0,6 . Isto revela que as séries de precipitações máximas anuais de 1 dia têm baixa assimetria. Os coeficientes de curtose estão situados entre 1,9 e 5,7, com média ponderada pela extensão da série de 3,3. Isto indica que, na média, a distribuição das precipitações máximas anuais de 1 dia é mesocúrtica.

\section{Análise de Freqüência de Chuvas Máximas de 1 Dia}

A análise dos coeficientes de assimetria e curtose das séries de chuvas máximas de 1 dia permitiu antever que as distribuições probabilísticas mais adequadas seriam Gumbel, Extremos Generalizada, Pearson Tipo 3, Log-Pearson tipo 3 e Gama Generalizada. Foi escolhida a distribuição probabilística de Gumbel, recomendada pela Eletrobrás (1987) para séries com coeficientes de assimetria inferior a 1,0 .

Para a análise regional das precipitações máximas de 1 dia foi utilizado o método do "indexflood". Para a estimativa do "index-flood" foi utilizada a média amostral das séries de precipitações máximas de 1 dia. Por sua vez as probabilidades associadas a cada elemento das séries de precipitações máximas, usualmente denominadas de posições de plotagem ou probabilidade empírica, foram definidas conforme recomendado por Cunnane (1978). A Figura 4 apresenta, graficamente, os precipitações máximas de 1 dia normalizados pela respectiva média (index-flood) plotados segundo Cunnane.

A análise da Figura 4 mostra que há uma tendência comum da distribuição empírica das precipitações máximas anuais de $1 \mathrm{dia}$, confirmando a adequabilidade da metodologia regional proposta.

Para o ajuste da distribuição probabilística Gumbel às precipitações máximas anuais dos postos selecionados foi utilizado o método dos momentos-L introduzido por Hosking (1990). Esta opção seguiu a recomendação da nova edição do Handbook of Hydrology (Stedinger,1992) que indica a utilização dos momentos-L para a estimativa dos parâmetros das distribuições probabilísticas na análise de freqüência de eventos extremos.

No entanto julgou-se mais adequado a aplicação desta metodologia para cada bacia utilizando os postos pluviométricos na sua área ou na imediata circunvizinhança. As Tabelas 5 a 8 apresentam os momentos-L e os coeficientes-L de variação e assimetria determinados para as séries de precipitações máximas de 1 dia normalizadas pelas respectivas médias. Os parâmetros da distribuição Gumbel para cada série de precipitações máximas normalizadas de 1 dia foram determinados utilizando os momentos-L $\lambda 1$ e $\lambda 2$. Finalmente os parâmetros da distribui- 
Tabela 5 - Momentos-L e Coeficientes-L das Séries de Precipitações Máximas da Bacia do Rio Juqueri

\begin{tabular}{|c|c|c|c|c|c|c|c|c|c|c|c|c|c|c|c|}
\hline \multirow{3}{*}{$\begin{array}{l}\text { momentos ponderados de } \\
\text { probabilidades }\end{array}$} & ELETROP & DAEE & DAEE & DAEE & DAEE & DAEE & DAEE & DAEE & DAEE & SABESP & \begin{tabular}{|l|} 
SABESP \\
\end{tabular} & SABESP & SABESP & SABESP & SABESP \\
\hline & \begin{tabular}{|l|} 
P12-097 \\
\end{tabular} & E3-225 & E3-005 & E3-047 & E3-083 & E3-030 & E3-082 & E3-081 & E3-262 & BRJ & P-1 & P-1A & $P-2$ & $\mathrm{P}-24$ & $P-3$ \\
\hline & 2346155 & 2346017 & 2346020 & 2346021 & 2346026 & 2346027 & 2346034 & 2346035 & 2346418 & & 2346136 & & 2346135 & & 2346134 \\
\hline$b o=$ & 1,00 & 1,00 & 1,00 & 1,00 & 1,00 & 1,00 & 1,00 & 1,00 & 1,00 &, 00 & 1,00 & 1,00 & 1,00 & 1,00 & 1,00 \\
\hline$b 1=$ & 0,56 & 0,54 & 56 & 57 & & & 0,57 & & 0,56 & 0,57 & 0,58 & 0,56 & 0,59 & 0,55 & 0,57 \\
\hline$b 2=$ & 0,40 & 0,37 & 0,40 & 0,40 & 0,40 & 0,43 & 0,41 & 0,40 & 0,40 & 0,41 & 0,42 & 0,40 & 0,43 & 0,39 & 0,41 \\
\hline momento & & & & & & & & & & & & & & & \\
\hline$\lambda 1=$ & 1,00 & 1,00 & 00 & 1,00 & 1,0 & $\overline{1, c}$ & 1,00 & 1,00 & 1,00 & 1,00 & 1,00 & 1,00 & $1,00 \mid$ & 1,00 & 1,00 \\
\hline$\lambda 2=$ & 0,12 & 0,08 & 0,12 & 0,13 & 0,13 & 0,1 & 0,14 & 0,12 & 0,12 & 0,14 & 0,17 & 0,13 & 0,18 & 0,11 & 0,14 \\
\hline $3=$ & 0,03 & 0,00 & 0,02 & 0,02 & 0,01 & 0,03 & 0,02 & 0,00 & 0,00 & 0,02 & 0,04 & 0,02 & 0,03 & 0,00 & 0,02 \\
\hline coeficie & & & & & & & & & & & & & & & \\
\hline $\mathrm{CV}$ t2 & 0,12 & 0,08 & 0,12 & 0,13 & 0,13 & 0,18 & 0,14 & 0,12 & 0,12 & 0,14 & 0,17 & 0,13 & 0,18 & 0,11 & 0,14 \\
\hline assimetria t3 $=$ & 0,21 & 0,00 & 0,17 & 0,13 & 0,11 & 0,18 & 0,13 & 0,04 & 0,02 & 0,14 & 0,21 & 0,15 & 0,19 & 0,03 & 7 \\
\hline
\end{tabular}

Tabela 6 - Momentos-L e Coeficientes-L das Séries de Precipitações Máximas da Bacia do Rio Atibainha

\begin{tabular}{|c|c|c|c|c|c|c|c|c|c|}
\hline \multirow{3}{*}{$\begin{array}{l}\text { momentos ponderados de } \\
\text { probabilidades }\end{array}$} & $\overline{D A E E}$ & ELETROP & \begin{tabular}{l|} 
ELETROP \\
\end{tabular} & DAEE & $\overline{\text { ANA }}$ & $\overline{\text { DAEE }}$ & SABESP & SABESP & SABESP \\
\hline & D3-070 & P8-191 & P12-081 & E3-099 & & E3-250 & BRA & P-5 & $P-6$ \\
\hline & 2246086 & 2346221 & 2346248 & 2346010 & 2346096 & 2346352 & & 2346403 & 2346402 \\
\hline bo $=$ & 1,00 & 1,00 & 1,00 & 1,00 & 1,00 & 1,00 & 1,00 & 1,00 & 1,00 \\
\hline $\mathrm{b} 1=$ & 0,56 & 0,60 & 0,56 & 0,56 & 0,53 & 0,56 & 0,56 & 0,56 & 0,57 \\
\hline $\mathrm{b} 2=$ & 0,40 & 0,44 & 0,40 & 0,40 & 0,37 & 0,40 & 0,39 & 0,40 & 0,40 \\
\hline \multicolumn{10}{|l|}{ momentos-L amostrais } \\
\hline$\lambda 1=$ & 1,00 & 1,00 & 1,00 & 1,00 & 1,00 & 1,00 & 1,00 & 1,00 & 1,00 \\
\hline$\lambda 2=$ & 0,12 & 0,20 & 0,13 & 0,13 & 0,07 & 0,12 & 0,12 & 0,12 & 0,14 \\
\hline$\lambda 3=$ & 0,01 & 0,03 & 0,00 & 0,01 & $-0,01$ & 0,01 & 0,00 & 0,03 & 0,02 \\
\hline \multicolumn{10}{|l|}{ coeficientes-L } \\
\hline$L-C V t 2=$ & 0,12 & 0,20 & 0,13 & 0,13 & 0,07 & 0,12 & 0,12 & 0,12 & 0,14 \\
\hline L-assimetria $\mathrm{t} 3=$ & 0,11 & 0,17 & 0,02 & 0,06 & $-0,08$ & 0,04 & 0,04 & 0,21 & 0,14 \\
\hline
\end{tabular}

Tabela 7- Momentos-L e Coeficientes-L das Séries de Precipitações Máximas da Bacia do Rio Cachoeira

\begin{tabular}{|c|c|c|c|c|c|c|c|c|c|}
\hline \multirow{3}{*}{$\begin{array}{l}\text { momentos ponderados de } \\
\text { probabilidades }\end{array}$} & DAEE & DAEE & DAEE & ANA & DAEE & SABESP & SABESP & SABESP & SABESP \\
\hline & D2-021 & D3-019 & E3-076 & 2346094 & E3-229 & BRC & P-15 & P-7 & $\mathrm{P}-4$ \\
\hline & 2245050 & 2246099 & 2346004 & 2346094 & 2346334 & & 2246140 & 2246134 & 2246046 \\
\hline $\mathrm{bo}=$ & 1,00 & 1,00 & 1,00 & 1,00 & 1,00 & 1,00 & 1,00 & 1,00 & 1,00 \\
\hline $\mathrm{b} 1=$ & 0,56 & 0,58 & 0,56 & 0,56 & 0,58 & 0,59 & 0,57 & 0,56 & 0,56 \\
\hline $\mathrm{b} 2=$ & 0,40 & 0,42 & 0,40 & 0,39 & 0,42 & 0,43 & 0,40 & 0,40 & 0,40 \\
\hline \multicolumn{10}{|l|}{ momentos-L amostrais } \\
\hline$\lambda 1=$ & 1,00 & 1,00 & 1,00 & 1,00 & 1,00 & 1,00 & 1,00 & 1,00 & 1,00 \\
\hline$\lambda 2=$ & 0,12 & 0,16 & 0,13 & 0,11 & 0,16 & 0,18 & 0,13 & 0,12 & 0,13 \\
\hline$\lambda 3=$ & 0,01 & 0,01 & 0,03 & 0,02 & 0,03 & 0,03 & 0,01 & 0,00 & 0,01 \\
\hline \multicolumn{10}{|l|}{ coeficientes-L } \\
\hline $\mathrm{L}-\mathrm{CV} \mathrm{t} 2=$ & 0,12 & 0,16 & 0,13 & 0,11 & 0,16 & 0,18 & 0,13 & 0,12 & 0,13 \\
\hline L-assimetria t3 = & 0,12 & 0,09 & 0,23 & 0,18 & 0,20 & 0,19 & 0,04 & 0,01 & 0,08 \\
\hline
\end{tabular}

Tabela 8 - Momentos-L e Coeficientes-L das Séries de Precipitações Máximas da Bacia do Rio Jaguari

\begin{tabular}{|c|c|c|c|c|c|c|c|c|c|c|c|c|}
\hline \multirow{3}{*}{$\begin{array}{l}\text { momentos ponderados de } \\
\text { probabilidades }\end{array}$} & DAEE & ANA & ANA & DAEE & DAEE & SABESP & SABESP & SABESP & SABESP & SABESP & SABESP & SABESP \\
\hline & D3-018 & & & D3-054 & D3-035 & $\mathrm{P}-10$ & P-11 & $\mathrm{P}-12$ & P-13 & P-8 & $\mathrm{P}-8 \mathrm{~A}$ & P-9 \\
\hline & 2246035 & 2246050 & 2246057 & 2246090 & 2246095 & 2246141 & 2246137 & 2246138 & 2246139 & 2246136 & & 2246135 \\
\hline bo $=$ & 1,00 & 1,00 & 1,00 & 1,00 & 1,00 & 1,00 & 1,00 & 1,00 & 1,00 & 1,00 & 1,00 & 1,00 \\
\hline $\mathrm{b} 1=$ & 0,58 & 0,59 & 0,56 & 0,58 & 0,59 & 0,56 & 0,55 & 0,56 & 0,57 & 0,56 & 0,57 & 0,57 \\
\hline $\mathrm{b} 2=$ & 0,42 & 0,42 & 0,39 & 0,42 & 0,42 & 0,39 & 0,39 & 0,40 & 0,41 & 0,40 & 0,40 & 0,41 \\
\hline \multicolumn{13}{|l|}{ momentos-L amostrais } \\
\hline$\lambda 1=$ & 1,00 & 1,00 & 1,00 & 1,00 & 1,00 & 1,00 & 1,00 & 1,00 & 1,00 & 1,00 & 1,00 & 1,00 \\
\hline$\lambda 2=$ & 0,17 & 0,17 & 0,11 & 0,16 & 0,18 & 0,11 & 0,11 & 0,12 & 0,15 & 0,12 & 0,13 & 0,15 \\
\hline$\lambda 3=$ & 0,03 & 0,02 & 0,01 & 0,03 & 0,02 & 0,00 & $-0,01$ & 0,00 & 0,00 & 0,02 & 0,02 & 0,03 \\
\hline \multicolumn{13}{|l|}{ coeficientes-L } \\
\hline $\mathrm{L}-\mathrm{CV}$ t2 $=$ & 0,17 & 0,17 & 0,11 & 0,16 & 0,18 & 0,11 & 0,11 & 0,12 & 0,15 & 0,12 & 0,13 & 0,15 \\
\hline L-assimetria $\mathrm{t} 3=$ & 0,18 & 0,10 & 0,11 & 0,20 & 0,10 & 0,03 & $-0,05$ & 0,01 & 0,02 & 0,18 & 0,17 & 0,23 \\
\hline
\end{tabular}


Tabela 9 - Precipitações Máximas da Bacia do Rio Juqueri

\begin{tabular}{|c|c|c|c|c|c|c|c|c|c|c|c|c|c|c|c|c|c|c|}
\hline \multirow{3}{*}{$\begin{array}{l}\text { Probabilidade } \\
\text { de Excedência }\end{array}$} & \multirow{3}{*}{$\begin{array}{l}\text { Período de } \\
\text { Retor no } \\
\text { (anos) }\end{array}$} & \multicolumn{2}{|c|}{$\begin{array}{l}\text { Precipitaçao Máxima / } \\
\text { Precipi tação Média }\end{array}$} & \multicolumn{15}{|c|}{ Preci pitaçãoMáxima (mm) -Bacia do Rio Juqueri } \\
\hline & & \multirow{2}{*}{ Gumbel } & \multirow{2}{*}{ Exponencial } & \begin{tabular}{|l|l|} 
P12-097 \\
\end{tabular} & E3-225 & E2-005 & E3-047 & E3-083 & E3-030 & E3.082 & E3-081 & E3-262 & BRJ & P-1 & P-1A & P-2 & $\mathrm{P}-24$ & P3 3 \\
\hline & & & & \begin{tabular}{|l|l|}
2346155 \\
\end{tabular} & 2346017 & 2346020 & 2346021 & 2346026 & 2346027 & 2346034 & 2346035 & 2346418 & & 2346136 & & 2346135 & & 2346134 \\
\hline 0,001 & 1.000 & 2,23 & 2,59 & 160 & 159 & 161 & 169 & 175 & 178 & 172 & 164 & 197 & 187 & 186 & 176 & 177 & 178 & 175 \\
\hline \multirow[t]{4}{*}{0,01} & 100 & 1,78 & 1,97 & 128 & 127 & 129 & 135 & 140 & 142 & 137 & 131 & 157 & 150 & 149 & 141 & 141 & 142 & 140 \\
\hline & & & & \multicolumn{12}{|c|}{ Precipitação Máxima ( $(\mathrm{mm}$ ) - Racia do RioJagua ri } & & & \\
\hline & & & & D3-018 & 2246050 & 2246057 & D3-054 & D3-035 & P-10 & P-11 & $\mathrm{P}-12$ & P-13 & P-8 & P-8A & P-9 & & & \\
\hline & & & & 2246035 & 2246050 & 2246057 & 2246090 & 2246095 & 2246141 & 2246137 & 2246138 & 2246139 & 2246136 & & 2246135 & & & \\
\hline 0,001 & 1.000 & 2,35 & 2,75 & 158 & 172 & 168 & 168 & 152 & 162 & 161 & 184 & 171 & 165 & 164 & 174 & & & \\
\hline \multirow[t]{4}{*}{0,01} & 100 & 1,86 & 2,07 & 125 & 136 & 132 & 133 & 120 & 128 & 127 & 146 & 135 & 131 & 130 & 137 & & & \\
\hline & & & & \multicolumn{9}{|c|}{ Precipi taçõo Máx ma (mm ) - Bacia do Ri oAti bainha } & & & & & & \\
\hline & & & & D3-070 & P8-191 & P12-081 & E3-099 & 2346096 & E3-250 & BRA & $\mathrm{P}-5$ & P-6 & & & & & & \\
\hline & & & & 2246086 & 2346221 & 2346248 & 2346010 & 2346096 & 2346352 & & 2346403 & 2346402 & & & & & & \\
\hline 0,001 & 1.000 & 2,16 & 2,50 & 172 & 209 & 160 & 155 & 148 & 161 & 156 & 184 & 173 & & & & & & \\
\hline \multirow[t]{4}{*}{0,01} & 100 & 1,74 & 1,92 & 138 & 168 & 128 & 125 & 119 & 129 & 125 & 148 & 139 & & & & & & \\
\hline & & & & \multicolumn{9}{|c|}{ Preci pita cão Mh́ xima (mm) - Bacia do Rio Cachoeira } & & & & & & \\
\hline & & & & D2-021 & D3-019 & E2-076 & 2346094 & Es-229 & BRC & P-15 & $\mathrm{P}-7$ & P-4 & & & & & & \\
\hline & & & & 2245050 & 2246099 & 2346004 & 2346094 & 2346334 & & 2246140 & 2246134 & 2246046 & & & & & & \\
\hline 0,001 & 1.000 & 2,23 & 2,59 & 181 & 163 & 158 & 153 & 170 & 188 & 168 & 171 & 182 & & & & & & \\
\hline 0,01 & 100 & 1,78 & 1,97 & 144 & 130 & 127 & 122 & 136 & 150 & 134 & 136 & 145 & & & & & & \\
\hline
\end{tabular}

ção Gumbel regional foram determinados utilizando o método proposto por Wallis (1982). Como exemplo, a Figura 5 apresenta a distribuição probabilística regional Gumbel ajustada pelos momentos-L para a bacia do rio Juqueri.

A Tabela 9 apresenta as precipitações máximas de 1 dia para as bacias dos rios Juqueri, Atibainha, Cachoeira e Jaguari-Jacareí para os períodos de retorno de 100 e 1.000 anos, obtidas pelo produto das ordenadas da distribuição probabilística Gumbel normalizada e da média amostral ponderada das precipitações máximas das séries, utilizando a extensão como fator de ponderação.

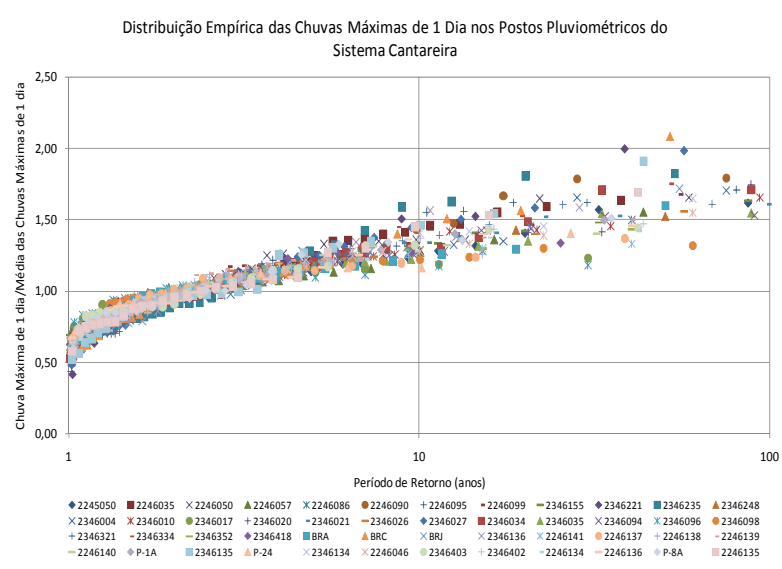

Figura 4 - Distribuição Empírica das Chuvas Máximas de 1 dia - Sistema Cantareira

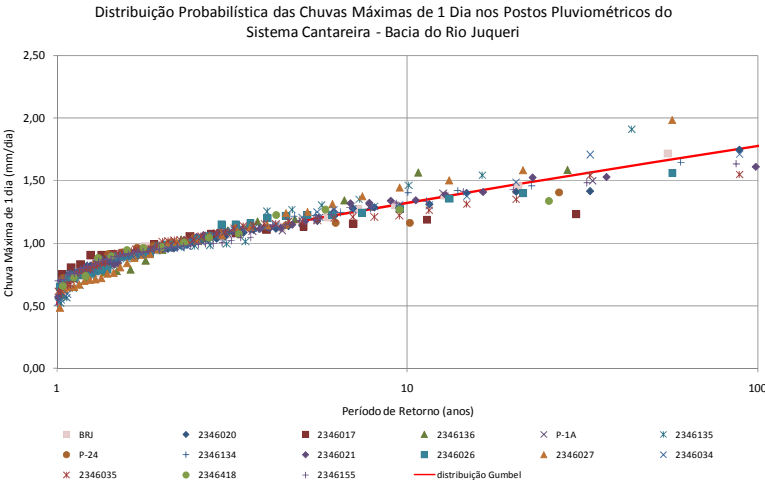

Figura 5 - Distribuição Empírica das Chuvas Máximas de 1 dia - Bacia do Rio Juqueri

\section{METODOLOGIA E CRITÉRIOS DE PROJETO}

A metodologia utilizada para a determinação dos hidrogramas de projeto para avaliação dos volumes de espera requeridos nos aproveitamentos do Sistema Cantareira foi definida em função das características fisiográficas das bacias e da disponibilidade de dados hidrológicos. Uma vez que as bacias hidrográficas têm áreas de drenagem entre 312 e $1.230 \mathrm{~km}^{2}$ e não dispõe de postos fluviográficos com séries longas de vazões médias diárias optou-se pela aplicação de modelo chuva-vazão que utilize as precipitações máximas e permita a representação das características fisiográficas da bacia.

A metodologia para a determinação dos hidrogramas de projeto é composta pelas seguintes etapas: 
- determinação das características fisiográficas das bacias hidrográficas e das sub-bacias do rio Jaguari, Cachoeira, Atibainha e Juqueri;

- utilização do hidrograma unitário sintético do "Soil Conservation Service" para a transformação da chuva excedente em escoamento superficial;

- escolha da duração crítica das precipitações de projeto para as bacias hidrográficas em função do tempo de concentração;

- escolha das distribuições temporais das precipitações de projeto para as bacias hidrográficas que resultem em condições críticas para formação do escoamento superficial;

- modelagem matemática e computacional das sub-bacias hidrográficas;

- simulação do processo chuva-vazão para a ocorrência das precipitações de projeto obtendo os respectivos hidrogramas de projeto;

- modelagem matemática e computacional da operação de cheia dos aproveitamentos do Jaguari-Jacareí, Cachoeira, Atibainha e Paiva Castro utilizando as relações cota $\mathrm{x}$ descarga dos vertedouros e as curvas cota $\mathrm{x}$ área $\mathrm{x}$ volume dos reservatórios;

- simulação da operação de cheia dos aproveitamentos do Jaguari-Jacareí, Cachoeira, Atibainha e Paiva Castro para hidrogramas de projeto associados ao período de retorno de 1.000 anos para a verificação da segurança hidrológica das barragens;

- simulação da operação de cheia dos aproveitamentos do Jaguari-Jacareí, Cachoeira, Atibainha e Paiva Castro para hidrogramas de projeto associados ao período de retorno de 100 anos para a verificação da capacidade de controle de cheias para diversas alternativas de vazões de restrição e volumes de espera;

- análise dos volumes de espera requeridos para a garantia da segurança da obra e controle de cheias a jusante dos aproveitamentos.

\section{TORMENTAS DE PROJETO}

\section{Duração}

A duração das chuvas ou tormentas de projeto dos aproveitamentos do Sistema Cantareira deve ser escolhida para garantir a plena contribui- ção das bacias hidrográficas e a formação de hidrogramas críticos ou de projeto para verificação da segurança hidrológica e da necessidade de utilizar volumes de espera. Uma vez que os aproveitamentos da bacia do rio Piracicaba - Jaguari-Jacareí, Cachoeira e Atibainha - têm grandes áreas e volumes de reservatórios para suas bacias hidrográficas há necessidade de utilizar de chuvas de projeto de longa duração que resultam em hidrogramas com maior volume e, portanto, mais críticos.

O tempo de concentração da bacia hidrográfica do rio Jaguari resultou em 18,2 horas. Por sua vez, os tempos de concentração das bacias dos rios Cachoeira, Atibainha e Juqueri resultaram em 8,6, 8,5 e 7,0 horas, respectivamente.

Desta forma, para atender as mencionadas diretrizes, foi escolhida uma tormenta de projeto para a bacia do rio Jaguari com duração de 24 horas, enquanto para as bacias dos rios Cachoeira, Atibainha e Juqueri foi utilizada uma duração de 12 horas.

\section{Distribuição Espacial}

As bacias hidrográficas dos rios Jaguari, Cachoeira, Atibainha e Juqueri têm áreas de drenagem de $1.230,392,312$ e $369 \mathrm{~km}^{2}$. Em função desta característica foi necessário, também, considerar as sub-bacias para representar a distribuição espacial das precipitações nas bacias hidrográficas.

Desconhecem-se estudos do fator de redução de área para o Estado de São Paulo, razão pela qual foram utilizadas as relações obtidas pelo National Environmental Research Council (1975). A aplicação desta referência indicou que as chuvas de projeto de 12 horas das bacias dos rios Juqueri e Cachoeira deveriam utilizar um fator de redução de 0,88 , enquanto para a bacia do rio Atibainha o fator resultou em 0,89 . Por sua vez as chuvas de projeto de 24 horas na bacia do rio Jaguari deveriam utilizar um fator de redução de 0,85 .

\section{Altura Pluviométrica}

As precipitações máximas de 1 dia associadas a períodos de retorno de 100 e 1.000 anos nas sub-bacias foram obtidas com base nas respectivas precipitações máximas de 1 dia dos postos pluviométricos localizados no seu interior e/ou nas proximidades. No entanto, há necessidade de determinar as precipitações máximas de 12 e 24 horas para estas sub-bacias.

Diversos estudos apresentados em publicações nacionais (Occhipinti, 1966) e internacionais (Sherman, 1939) têm demonstrado que a chuva de 
RBRH - Revista Brasileira de Recursos Hidricos Volume 16 n.3-Jul/Set 2011, 05-26

Tabela 10 - Precipitações Máximas de Projeto nas Sub-Bacias

\begin{tabular}{|c|c|c|c|c|c|c|c|c|c|}
\hline \multirow{2}{*}{$\begin{array}{l}\text { Bacias e Sub- } \\
\text { Bacias }\end{array}$} & \multirow{2}{*}{$\begin{array}{c}\text { Area de } \\
\text { Drenagem } \\
\left(\mathrm{km}^{2}\right)\end{array}$} & \multicolumn{2}{|c|}{$\begin{array}{c}\text { Chuva no Ponto de } 1 \text { dia } \\
\text { ou } 12 \text { horas (mm) }\end{array}$} & \multicolumn{2}{|c|}{$\begin{array}{c}\text { Chuva no Ponto de } 1 \text { dia } \\
\text { ou } 24 \text { horas ( } \mathrm{mm})\end{array}$} & \multicolumn{2}{|c|}{$\begin{array}{c}\text { Chuva na Área de } 1 \text { dia ou } \\
12 \text { horas }(\mathrm{mm})\end{array}$} & \multicolumn{2}{|c|}{$\begin{array}{c}\text { Chuva na Área de } 1 \text { dia ou } \\
24 \text { horas }(\mathrm{mm})\end{array}$} \\
\hline & & 100 anos & 1.000 anos & 100 anos & 1.000 anos & 100 anos & 1.000 anos & 100 anos & 1.000 anos \\
\hline JUQ 1 & 108,7 & 127 & 159 & 144 & 180 & 112 & 140 & 132 & 165 \\
\hline JUQ 2 & 104,2 & 140 & 175 & 159 & 199 & 124 & 155 & 146 & 183 \\
\hline JUQ 3 & 156,1 & 127 & 159 & 145 & 181 & 113 & 141 & 133 & 166 \\
\hline JUQUERI & 369,0 & & & & & 116 & 145 & & \\
\hline ATIB 1 & 1388 & \begin{tabular}{l|}
143 \\
\end{tabular} & 178 & 163 & 202 & 127 & 158 & 150 & 186 \\
\hline ATIB 2 & 173,2 & 132 & 164 & 150 & 186 & 117 & 145 & 138 & 171 \\
\hline ATIBAINHA & 312,0 & & & & & 121 & 151 & & \\
\hline & & & & & & & & & \\
\hline CACH 1 & 25,7 & 139 & 174 & 158 & 197 & 122 & 153 & 145 & 181 \\
\hline $\mathrm{CACH} 2$ & 28,1 & 145 & 181 & 165 & 206 & 128 & 160 & 151 & 189 \\
\hline CACH 3 & 77,0 & 142 & 177 & 161 & 201 & 125 & 156 & 147 & 184 \\
\hline CACH 4 & 147,6 & 134 & 168 & 153 & 191 & 119 & 148 & 140 & 175 \\
\hline CACH 5 & 113,5 & 141 & 176 & 160 & 201 & 124 & 156 & 147 & 184 \\
\hline CACHOEIRA & 392,0 & & & & & 122 & 153 & & \\
\hline & & & & & & & & & \\
\hline JAG 1 & 12,2 & 135 & 171 & 154 & 194 & 114 & 145 & 136 & 172 \\
\hline JAG 2 & 9,6 & 135 & 171 & 154 & 194 & 114 & 145 & 136 & 172 \\
\hline JAG 3 & 57,5 & 135 & 171 & 154 & 194 & 114 & 145 & 136 & 172 \\
\hline JAG 4 & 32,3 & 135 & 171 & 154 & 194 & 114 & 145 & 136 & 172 \\
\hline JAG 5 & 58,0 & 135 & 171 & 154 & 194 & 114 & 145 & 136 & 172 \\
\hline JAG 6 & 99,5 & 141 & 178 & 160 & 202 & 119 & 150 & 142 & 179 \\
\hline JAG 7 & 136,0 & 130 & 164 & 147 & 186 & 110 & 139 & 131 & 165 \\
\hline JAG 8 & 5,7 & 135 & 171 & 154 & 194 & 114 & 145 & 136 & 172 \\
\hline JAG 9 & 15,2 & 135 & 171 & 154 & 194 & 114 & 145 & 136 & 172 \\
\hline JAG 10 & 218,9 & 132 & 167 & 150 & 189 & 111 & 141 & 133 & 168 \\
\hline JAG 11 & 157,1 & 127 & 161 & 145 & 183 & 108 & 136 & 128 & 162 \\
\hline JAG 12 & 111,1 & 137 & 174 & 156 & 197 & 116 & 147 & 138 & 175 \\
\hline JAG 13 & 114,2 & 129 & 163 & 146 & 185 & 109 & 138 & 130 & 164 \\
\hline JAC1 (JACAREÍ) & 202,8 & 133 & 168 & 151 & 191 & 112 & 142 & 134 & 169 \\
\hline JAGUARI & 1027,2 & & & & & & & & \\
\hline JAGUARI- JACAREÍ & 1230,0 & & & & & & & 134 & 169 \\
\hline
\end{tabular}

Tabela 11- Parâmetros do Método de Muskingum

\begin{tabular}{|c|c|c|c|c|c|c|c|}
\hline \multirow{2}{*}{$\begin{array}{c}\text { Composição dos hidrogramas das sub- } \\
\text { bacias }\end{array}$} & Comprimento de & & \multirow[b]{2}{*}{$\begin{array}{l}\text { Velocidade } \\
\text { Média }(\mathrm{m} / \mathrm{s})\end{array}$} & \multirow{2}{*}{$\begin{array}{c}\text { Velocidade } \\
\text { Média da Onda } \\
(\mathrm{m} / \mathrm{s})\end{array}$} & \multirow{2}{*}{$\begin{array}{l}\text { Tempo de } \\
\text { Translação da } \\
\text { Onda K (h) }\end{array}$} & \multirow[b]{2}{*}{$\begin{array}{c}\text { número de } \\
\text { trechos }\end{array}$} & \multirow[b]{2}{*}{$\mathrm{x}$} \\
\hline & $\begin{array}{l}\text { propagação } \\
(\mathbf{k m})\end{array}$ & Hidrograma Resultante & & & & & \\
\hline$(\mathrm{J} 1+\mathrm{J} 2)$ & 12,4 & J1-2 & 1,5 & 2,5 & 0,18 & 8 & 0,2 \\
\hline $\mathrm{J} 1-2+(\mathrm{J} 3+\mathrm{J} 4)$ & 20,9 & J1-2-3-4 & 1,4 & 2,4 & 0,15 & 16 & 0,2 \\
\hline $\mathrm{J1} 1-2-3-4+(\mathrm{J} 5+\mathrm{J} 6)$ & 47,0 & J1-2-3-4-5-6 & 1,7 & 2,8 & 0,20 & 24 & 0,2 \\
\hline JAG 8 + JAG 9 & 46,3 & J8-9 & 1,7 & 2,8 & 0,19 & 24 & 0,2 \\
\hline J8-9 + JAG 10 & 16,0 & J8-9-10 & 1,6 & 2,6 & 0,21 & 8 & 0,2 \\
\hline J8-9-10+ JAG 11 & 7,7 & J8-9-10-11 & 1,6 & 2,6 & 0,21 & 4 & 0,2 \\
\hline J8-9-10-11 + JAG 7 + JAG 12 & 32,0 & J8-9-10-11-7-12 & 1,6 & 2,6 & 0,21 & 16 & 0,2 \\
\hline Total (J8-9-10-11-7-12 + J13) & & Jtotal & & & & & \\
\hline JAC1 (JACAREÍ) & & JACtotal & & & & & \\
\hline $\mathrm{C} 1+\mathrm{C} 2$ & 19,6 & C1-2 & 1,5 & 2,6 & 0,21 & 10 & 0,2 \\
\hline $\mathrm{C} 1-2+\mathrm{C} 3+\mathrm{C} 4$ & 23,2 & C1-2-3-4 & 1,0 & 1,6 & 0,22 & 18 & 0,2 \\
\hline Total (C1-2-3-4 + C5) & & Ctotal & & & & & \\
\hline A1 & 17,5 & AT1 & 1,3 & 2,1 & 0,19 & 12 & 0,2 \\
\hline Total (AT1+ A2) & & Atotal & & & & & \\
\hline $\mathrm{JU} 1+\mathrm{JU} 2$ & 12,6 & JU1-2 & 1,4 & 2,3 & 0,19 & 8 & 0,2 \\
\hline Total (JU1-2+ JU3) & & JUTotal & & & & & \\
\hline
\end{tabular}


1 dia tem uma duração efetiva média de 12 horas. Portanto, foi adotado este critério, que possibilitou a determinação das chuvas máximas de 12 horas com base nas chuvas máximas de 1 dia.

As mencionadas publicações apresentam, também, as relações entre as precipitações máximas de 1 dia e 24 horas na cidade de São Paulo. Da mesma forma a publicação de Pfafstetter (1982) também permite avaliar esta relação em outros locais do Brasil. Estas publicações mostram que as precipitações máximas de 1 dia e 24 horas resultam, com muita freqüência, em 0,88 , indicando que a precipitação máxima do período de 24 horas contínuo é cerca de 13,6\% superior à precipitação máxima observada diariamente. Desta forma foi utilizado este critério para a determinação das chuvas máximas de 24 horas com base nas chuvas máximas de 1 dia.

Finalmente foram aplicados os mencionados fatores de redução de área, permitindo obter as alturas pluviométricas ou precipitações máximas de projeto associadas a períodos de retorno de 100 e 1.000 anos nas sub-bacias das bacias hidrográficas dos rios Jaguari/Jacareí, Cachoeira, Atibainha e Juqueri nos aproveitamentos do Sistema Cantareira, apresentadas na Tabela 10. Em destaque estão as precipitações máximas de projeto.

\section{Distribuição Temporal}

A distribuição temporal dos volumes precipitados condiciona o volume infiltrado e a forma do hidrograma de escoamento superficial direto originado pela chuva excedente.

Para este estudo optou-se por utilizar os gráficos adimensionais de altura pluviométrica acumulada em função da duração, definidos por Magni e Mero (1986). Na região do Sistema Cantareira os gráficos adimensionais são apresentados para São Paulo, Aparecida e Piracicaba. Nestes gráficos são destacadas a envoltória superior, que representa as chuvas que iniciam com grande intensidade diminuindo com o tempo, e a envoltória inferior que representa as chuvas que iniciam com pequena intensidade e aumentam gradativamente com o tempo.

Para representar a distribuição temporal crítica das chuvas intensas nas bacias hidrográficas dos rios Jaguari/Jacareí, Cachoeira, Atibainha e Juqueri nos aproveitamentos do Sistema Cantareira optou-se por utilizar a média das envoltórias superiores das distribuições temporais das chuvas intensas com duração superior a 6 horas para São Paulo e Aparecida devido a maior proximidade da região, representada na Figura 6.

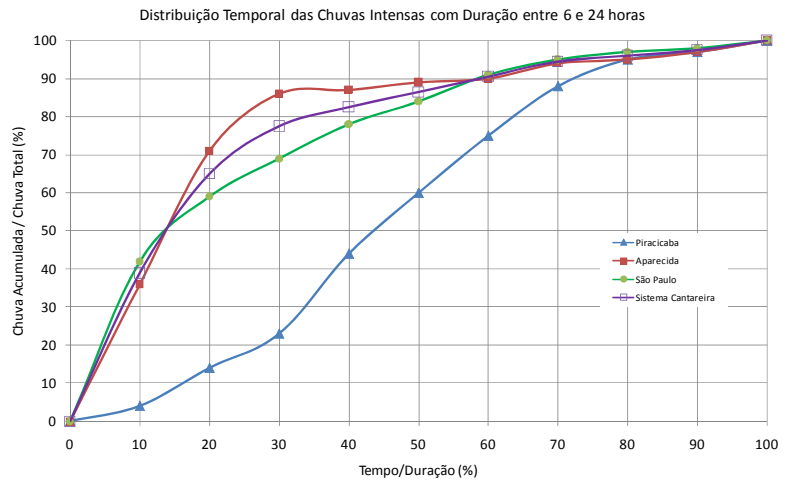

Figura 6 - Distribuição Temporal das Chuvas Intensas

\section{DETERMINAÇÃO DOS HIDROGRAMAS DE PROJETO}

\section{Método e Parâmetros para Propagação dos Hidrogramas}

Os hidrogramas calculados nas sub-bacias de montante precisam ser propagados no trecho de rio a jusante para serem somados aos hidrogramas provenientes das áreas de contribuição das sub-bacias a jusante. Para esta propagação foi utilizado o método de Muskingum. Para a aplicação deste método foram determinados, através de ferramentas de geoprocessamento, o comprimento do talvegue do rio principal entre as seções de propagação.

A Tabela 11 apresenta os dados e os parâmetros $\mathrm{K}$, X e número de trechos determinados para a aplicação do método de Muskingum. O parâmetro $\mathrm{K}$ representa o tempo médio de deslocamento da onda de cheia e $\mathrm{X}$ representa o peso da integração da vazão no espaço. A velocidade de escoamento foi obtida utilizando o comprimento do talvegue e o tempo de concentração da sub-bacia. A velocidade média da onda de translação foi obtida multiplicando por 5/3 a velocidade de escoamento considerando o canal como sendo retangular e largo. Desta forma, foi possível obter o tempo de translação da onda $\mathrm{K}$ utilizando a velocidade média da onda e o comprimento do talvegue do rio principal. Foi adotado o valor de 0,2 para o parâmetro $\mathrm{X}$ do método de Muskingum, recomendado para canais em condições naturais.

O número de trechos foi obtido de forma a garantir a estabilidade numérica do método de Muskingum. O intervalo de tempo de simulação $\Delta t$ adotado foi de 6 minutos.

Ressalta-se que a propagação do hidrograma da sub-bacia ATIB2 para a seção da barragem do 
Tabela 12 - Síntese dos Hidrogramas das Bacias do Sistema Cantareira

\begin{tabular}{|l|r|r|r|r|r|r|r|r|}
\hline \multirow{2}{*}{ Resultados } & \multicolumn{2}{|c|}{ Bacia do Rio Jaguari } & \multicolumn{2}{|c|}{ Bacia do Rio Cachoeira } & \multicolumn{2}{|c|}{ Bacia do Rio Atibainha } & \multicolumn{2}{c|}{ Bacia do Rio Juqueri } \\
\cline { 2 - 10 } & 100 anos & 1.000 anos & 100 anos & 1.000 anos & 100 anos & 1.000 anos & 100 anos & 1.000 anos \\
\hline total precipitado $(\mathrm{mm})$ & 134 & 169 & 122 & 153 & 121 & 151 & 116 & 145 \\
\hline infiltração ou perda total $(\mathrm{mm})$ & 76 & 83 & 74 & 82 & 70 & 76 & 68 & 74 \\
\hline excedente total $(\mathrm{mm})$ & 58 & 86 & 48 & 71 & 51 & 74 & 48 & 70 \\
\hline & & & & & & & & \\
\hline total precipitado $\left(10^{3} \mathrm{~m}^{3}\right)$ & 164.356 & 207.889 & 47.977 & 60.060 & 37.853 & 47.071 & 42.626 & 53.339 \\
\hline infiltração ou perda total $\left(10^{3} \mathrm{~m}^{3}\right)$ & 93.338 & 102.530 & 29.140 & 32.102 & 21.826 & 23.859 & 24.999 & 27.430 \\
\hline excedente total $\left(10^{3} \mathrm{~m}^{3}\right)$ & 71.018 & 105.360 & 18.837 & 27.957 & 16.027 & 23.212 & 17.628 & 25.909 \\
\hline volume do hidrograma $\left(10^{3} \mathrm{~m}^{3}\right)$ & 71.018 & 105.360 & 18.837 & 27.957 & 16.027 & 23.212 & 17.628 & 25.909 \\
\hline & & & & & & & & \\
\hline
\end{tabular}

Atibainha foi desconsiderada uma vez que o braço do reservatório atinge seu exutório não havendo, na prática, trecho de translação.

\section{Modelagem Computacional}

A modelagem computacional foi desenvolvida utilizando o modelo HEC-HMS v. 3.2 desenvolvido pelo Hydrologic Engineering Center do US Corps of Engineers. A modelagem computacional considerou as sub-bacias representadas na Figura 1, com suas conexões representadas por trechos em canal.

Para a modelagem das sub-bacias hidrográficas foram fornecidas as características fisiográficas representadas pelas áreas de drenagem, o tempo de retardo e o número da curva $\mathrm{CN}$, apresentados na Tabela 4. Para representar os trechos em canal foram fornecidos os parâmetros do método de Muskingum apresentados na Tabela 11.

As tormentas foram representadas fornecendo os totais precipitados máximos de 12 horas nas sub-bacias dos rios Cachoeira, Atibainha e Juqueri e 24 horas nas sub-bacias do rio Jaguari, apresentados em destaque na Tabela 10 . Os totais precipitados máximos foram distribuídos no tempo utilizando a distribuição temporal acumulada apresentada na Figura 6 com indicação "Sistema Cantareira”.

O intervalo de tempo de simulação adotado foi de 6 minutos. O período de simulação foi de 24 horas para as bacias dos rios Cachoeira, Atibainha e Juqueri e 48 horas para a bacia do rio Jaguari.

\section{Hidrogramas de Projeto}

As simulações do processo chuva-vazão das bacias dos rios Jaguari, Cachoeira, Atibainha e Ju- queri nos aproveitamentos foram desenvolvidas para as tormentas de projeto de 12 ou 24 horas de duração e períodos de retorno de 100 e 1.000 anos.

A Tabela 12 apresenta a síntese dos resultados das simulações do processo chuva-vazão das bacias dos rios Jaguari, Cachoeira, Atibainha e Juqueri, fornecendo para cada condição de projeto os totais precipitados, os totais infiltrados e os excedentes, bem como os volumes e as vazões de pico dos hidrogramas resultantes.

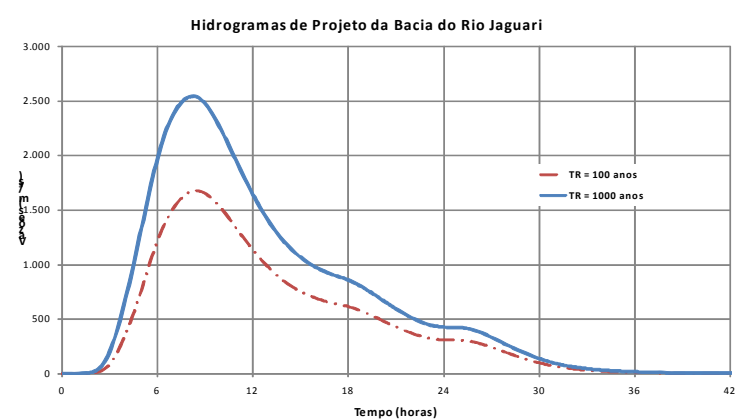

Figura 7 - Hidrogramas de Projeto - Bacia Jaguari

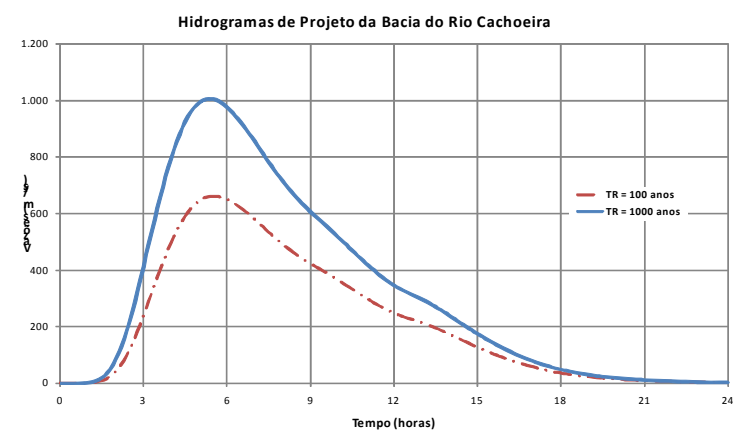

Figura 8 - Hidrogramas de Projeto - Bacia Cachoeira 
As Figuras 7 a 10 apresentam os hidrogramas de projeto associadas aos períodos de retorno de 100 e 1.000 anos das bacias dos rios Jaguari, Cachoeira, Atibainha e Juqueri nos aproveitamentos.

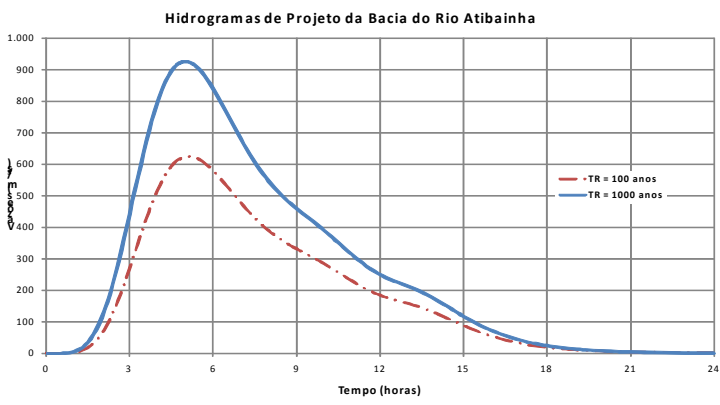

Figura 9 - Hidrogramas de Projeto - Bacia Atibainha

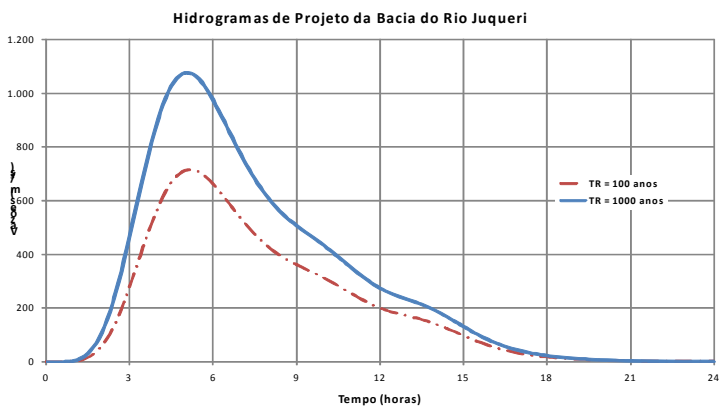

Figura 10 - Hidrogramas de Projeto - Bacia Juqueri

\section{DADOS OPERACIONAIS DOS APROVEITAMENTOS}

\section{Relações Cota x Área x Volume}

Para fins do objetivo deste estudo foram utilizadas as relações cota $\mathrm{x}$ área $\mathrm{x}$ volume dos reservatórios obtidas recentemente no levantamento desenvolvido pela Azimute para a SABESP (Azimute, 2008).

\section{Relações Cota x Descarga dos Vertedouros}

Foram utilizadas as relações cota $\mathrm{x}$ descarga apresentados no DATA OPER Sistema Cantareira (1991).

\section{Dados Operacionais}

Os dados operacionais dos aproveitamentos do Sistema Cantareira são apresentados na Tabela
13, incluindo as cotas de coroamento do vertedouro e da barragem, os NA mínimo e máximo operacionais e os volumes mínimo, máximo e útil dos reservatórios.

Tabela 13- Dados Operacionais dos Aproveitamentos

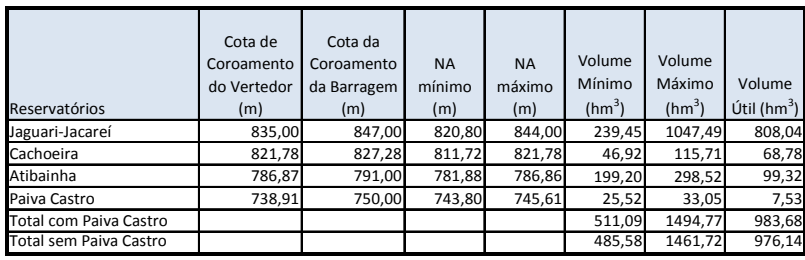

\section{ANÁLISE DA SEGURANÇA HIDROLÓGICA DAS BARRAGENS}

Os estudos hidrológicos para análise do volume de espera dos reservatórios do Sistema Cantareira foram iniciados considerando a garantia da segurança hidrológica dos aproveitamentos, entendida como aquela que evitaria acidentes decorrentes de cheias.

Para esta análise foram feitas a modelagem computacional e as simulações da operação dos reservatórios considerando os hidrogramas de cheia com período de retorno de 1.000 anos. Para a modelagem computacional foram utilizadas as relações cota $\mathrm{x}$ volume dos reservatórios e as relações cota $\mathrm{x}$ descarga máxima dos vertedouros.

As análises iniciais não consideraram volumes de espera nos reservatórios. Assim, a condição inicial dos reservatórios correspondeu ao NA máximo normal.

As Figuras 11 a 14 apresentam os hidrogramas afluentes e efluentes e o limnigrama dos reservatórios do Sistema Cantareira resultantes da operação para a cheia com período de retorno de 1.000 anos. A Tabela 14 apresenta um resumo dos resultados das simulações da operação dos reservatórios para o hidrograma de projeto com período de retorno de 1.000 anos.

Os resultados indicam que os reservatórios do Sistema Cantareira provocam um amortecimento expressivo no hidrograma afluente, ficando entre 57 e $95 \%$. Este amortecimento é resultado da grande capacidade de armazenamento do reservatório e a limitação de descarga das estruturas de vertimento. A sobrelevação dos reservatórios Jaguari-Jacareí e Atibainha fica abaixo de 1,0 m enquanto nos reser- 
vatórios Cachoeira e Paiva Castro atingem 2,40 e $2,55 \mathrm{~m}$.

Tabela 14- Resumo dos Resultados da Simulação da Operação para o Hidrograma de Projeto - 1.000 anos

\begin{tabular}{|l|r|r|r|r|}
\hline Parâmetros & $\begin{array}{c}\text { Jaguari- } \\
\text { Jacareí }\end{array}$ & Cachoeira & Atibainha & Paiva Castro \\
\hline cota de coroamento do vertedouro $(\mathrm{m})$ & 835,00 & 821,78 & 786,87 & 738,91 \\
\hline NA máximo normal $(\mathrm{m})$ & 844,00 & 821,78 & 786,86 & 745,61 \\
\hline cota de coroamento da barragem $(\mathrm{m})$ & 847,00 & 827,28 & 791,00 & 750,00 \\
\hline & & & & \\
\hline & 2.543 & 1.006 & 926 & 1.077 \\
\hline Vazão de Pico do hidrograma afluente $\left(\mathrm{m}^{3} / \mathrm{s}\right)$ & 105.360 & 27.957 & 23.212 & 25.909 \\
\hline volume do hidrograma afluente $\left(10^{3} \mathrm{~m}^{3}\right)$ & & & & \\
\hline & 1.102 & 165 & 46 & 259 \\
\hline Vazão de Pico do hidrograma efluente $\left(\mathrm{m}^{3} / \mathrm{s}\right)$ & 844,61 & 824,18 & 787,82 & 748,16 \\
\hline NA máximo no reservatório $(\mathrm{m})$ & 30.408 & 21.204 & 21.433 & 13.680 \\
\hline volume máximo armazenado no reservatório $\left(10^{3} \mathrm{~m}^{3}\right)$ & & & & \\
\hline & 57 & 84 & 95 & 76 \\
\hline amortecimento da vazão de pico $(\%)$ & 29 & 76 & 92 & 53 \\
\hline volume máximo armazenado/volume afluente $(\%)$ & 0,61 & 2,40 & 0,96 & 2,55 \\
\hline sobrelevação do NA do reservatório $(\mathrm{m})$ & 2,39 & 3,10 & 3,18 & 1,84 \\
\hline bordo-livre $(\mathrm{m})$ & & &
\end{tabular}

Quanto à segurança verifica-se que os reservatórios do Sistema Cantareira mantêm uma bordalivre, diferença entre a cota de coroamento da barragem e o NA máximo do reservatório, entre 1,84 e $3,18 \mathrm{~m}$. Portanto, a borda-livre é suficiente para garantir a segurança hidrológica dos aproveitamentos do Sistema Cantareira, não havendo necessidade de considerar volumes de espera para este objetivo.

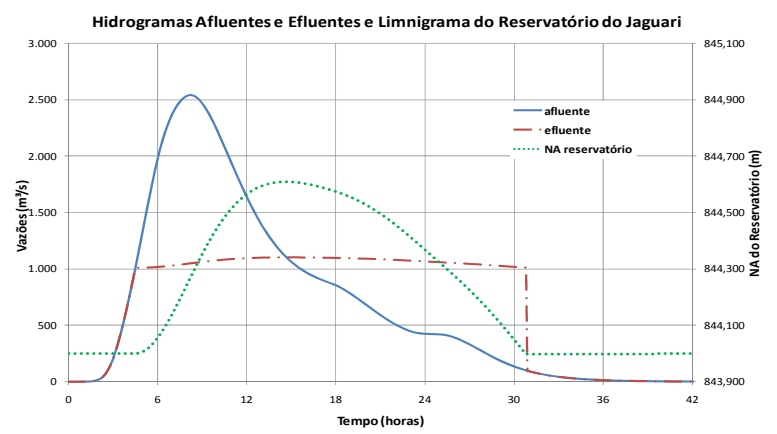

Figura 11 - Hidrogramas Afluentes e Efluentes Reservatório Jaguari

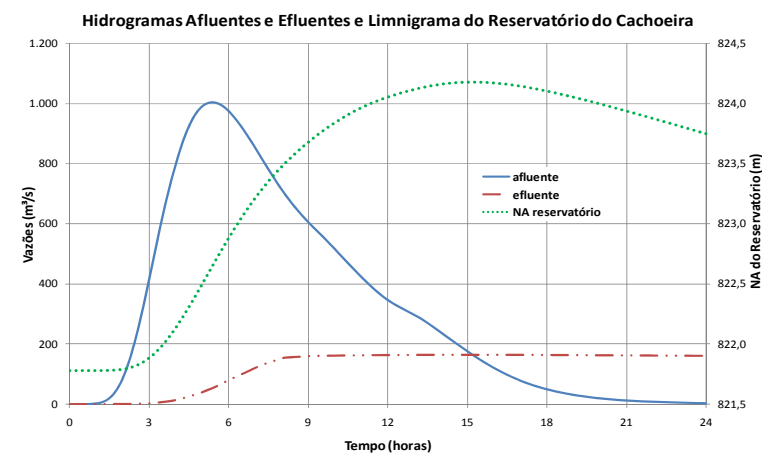

Figura 12 - Hidrogramas Afluentes e Efluentes Reservatório Cachoeira

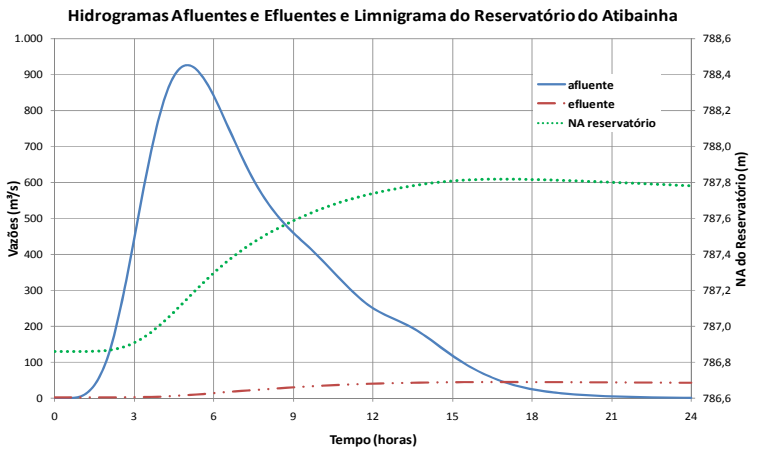

Figura 13 - Hidrogramas Afluentes e Efluentes Reservatório Atibainha

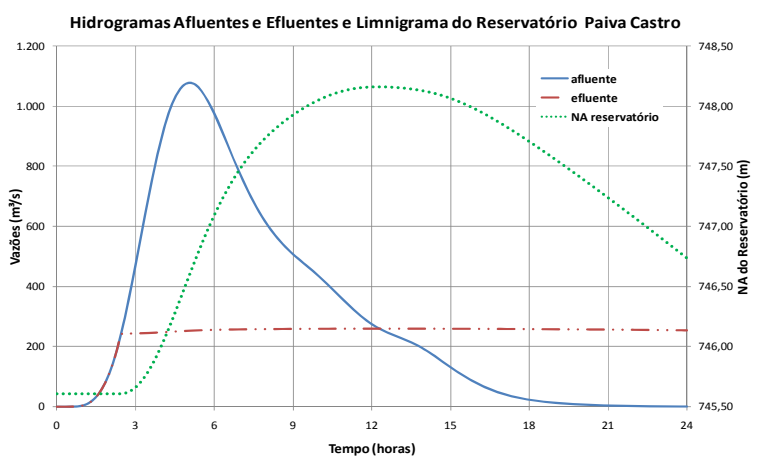

Figura 14 - Hidrogramas Afluentes e Efluentes Reservatório Paiva Castro

\section{ANÁLISE DOS VOLUMES DE ESPERA}

\section{Vazões de Restrição}

A vazão de restrição corresponde à vazão máxima efluente do reservatório que evita impactos a jusante. A vazão de restrição é usualmente determinada através de análise de campo e campanhas hidrométricas, bem como modelagem e simulações hidrodinâmicas.

A SABESP informou as seguintes vazões de restrição para os aproveitamentos do Sistema Cantareira:

- Jaguari-Jacareí: $50 \mathrm{~m}^{3} / \mathrm{s}$;

- Cachoeira: $7 \mathrm{~m}^{3} / \mathrm{s}$

- Atibainha: $2 \mathrm{~m}^{3} / \mathrm{s}$;

- Paiva Castro: $3 \mathrm{~m}^{3} / \mathrm{s}$.

Estas vazões correspondem a uma prática de operação mais rotineira da empresa e não obedecem ao conceito do que normalmente se entende por vazão de restrição. Em rios aluviais, o leito me- 
Tabela 15 - Resultados das Simulações de Controle de Cheias dos Reservatórios do Sistema Cantareira

Reservatório Juqueri-Paiva Castro

\begin{tabular}{|c|c|c|c|c|c|c|c|c|c|}
\hline \multicolumn{3}{|c|}{ NA máximo normal $(\mathrm{m})=$} & 745,61 & \multicolumn{5}{|c|}{ Cota de Coroamento da Barragem $(\mathrm{m})=$} & 750,00 \\
\hline \multicolumn{3}{|c|}{ Volume no NA máximo normal $\left(\mathrm{hm}^{3}\right)=$} & 33,05 & \multicolumn{5}{|c|}{ NA máximo na cheia milenar $(\mathrm{m})=$} & 748,16 \\
\hline \multicolumn{3}{|c|}{ Volume Útil $\left(\mathrm{hm}^{3}\right)=$} & 7,53 & \multicolumn{5}{|c|}{3 Vazão Máxima Efluente na cheia milenar $\left(\mathrm{m}^{3} / \mathrm{s}\right)=$} & 258,6 \\
\hline \multirow{3}{*}{$\begin{array}{c}\text { NA inicial } \\
(\mathrm{m})\end{array}$} & \multirow{3}{*}{$\begin{array}{c}\text { Volume de } \\
\text { Espera }\left(\mathrm{hm}^{3}\right)\end{array}$} & \multirow{3}{*}{\begin{tabular}{|c|} 
Volume de \\
$\begin{array}{c}\text { Espera / Volume } \\
\text { Útil (\%) }\end{array}$
\end{tabular}} & \multicolumn{7}{|c|}{ NA máximo no reservatório (m) } \\
\hline & & & \multicolumn{7}{|c|}{ Vazão de Restrição $\left(\mathrm{m}^{3} / \mathrm{s}\right)$} \\
\hline & & & 3,0 & 5,0 & 10,0 & 15,0 & 20,0 & 25,0 & 30,0 \\
\hline 745,61 & 0,00 & 0,00 & 748,771 & 748,747 & 748,689 & 748,634 & 748,581 & 748,529 & 748,478 \\
\hline 745,00 & 2,72 & 36,05 & 748,324 & 748,300 & 748,242 & 748,187 & 748,134 & 748,082 & 748,031 \\
\hline 744,75 & 3,77 & 50,06 & 748,150 & 748,126 & 748,068 & 748,013 & 747,958 & 747,904 & 747,850 \\
\hline 744,50 & 4,80 & 63,67 & 747,982 & 747,957 & 747,896 & 747,838 & 747,782 & 747,728 & 747,674 \\
\hline 744,25 & 5,79 & 76,92 & 747,808 & 747,783 & 747,722 & 747,664 & 747,608 & 747,554 & 747,500 \\
\hline
\end{tabular}

\section{Reservatório Atibainha}

\begin{tabular}{|c|c|c|c|c|c|c|c|c|c|}
\hline \multicolumn{3}{|c|}{ NA máximo normal $(\mathrm{m})=$} & 786,86 & \multicolumn{5}{|c|}{ Cota de Coroamento da Barragem $(\mathrm{m})=$} & 791,00 \\
\hline \multicolumn{3}{|c|}{ Volume no NA máximo normal $\left(\mathrm{hm}^{3}\right)=$} & 298,52 & \multicolumn{5}{|c|}{ NA máximo na cheia milenar $(\mathrm{m})=$} & 787,82 \\
\hline \multicolumn{3}{|c|}{ Volume Útil $\left(\mathrm{hm}^{3}\right)=$} & 99,32 & \multicolumn{5}{|c|}{ Vazão Máxima Efluente na cheia milenar $\left(\mathrm{m}^{3} / \mathrm{s}\right)=$} & 45,5 \\
\hline \multirow{3}{*}{$\begin{array}{c}\text { NA inicial } \\
(\mathrm{m})\end{array}$} & \multirow{3}{*}{$\begin{array}{c}\text { Volume de } \\
\text { Espera }\left(\mathrm{hm}^{3}\right)\end{array}$} & \multirow{3}{*}{\begin{tabular}{|c|} 
Volume de \\
Espera / Volume \\
Útil (\%)
\end{tabular}} & \multicolumn{7}{|c|}{ NA máximo no reservatório $(\mathrm{m})$} \\
\hline & & & \multicolumn{7}{|c|}{ Vazão de Restrição $\left(\mathrm{m}^{3} / \mathrm{s}\right)$} \\
\hline & & & 2,0 & 5,0 & 10,0 & 15,0 & 20,0 & 25,0 & 30,0 \\
\hline 786,86 & 0,00 & 0,00 & 787,573 & 787,564 & 787,550 & 787,537 & 787,524 & 787,512 & 787,500 \\
\hline 786,75 & 2,41 & 2,43 & 787,467 & 787,459 & 787,446 & 787,435 & 787,423 & 787,413 & 787,402 \\
\hline 786,50 & 7,85 & 7,90 & 787,225 & 787,218 & 787,208 & 787,198 & 787,189 & 787,181 & 787,172 \\
\hline 786,25 & 13,23 & 13,32 & 786,983 & 786,979 & 786,973 & 786,968 & 786,963 & 786,959 & 786,955 \\
\hline 786,00 & 18,57 & 18,69 & 786,501 & 786,501 & 786,501 & 786,501 & 786,501 & 786,501 & 786,501 \\
\hline
\end{tabular}

\section{Reservatório Cachoeira}

\begin{tabular}{|c|c|c|c|c|c|c|c|c|c|}
\hline \multicolumn{3}{|c|}{ NA máximo normal $(\mathrm{m})=$} & 821,78 & \multicolumn{5}{|c|}{ Cota de Coroamento da Barragem $(\mathrm{m})=$} & 827,28 \\
\hline \multicolumn{3}{|c|}{ Volume no NA máximo normal $\left(\mathrm{hm}^{3}\right)=$} & 115,71 & \multicolumn{5}{|c|}{ NA máximo na cheia milenar $(\mathrm{m})=$} & 824,18 \\
\hline \multicolumn{3}{|c|}{ Volume Útil $\left(\mathrm{hm}^{3}\right)=$} & 68,78 & \multicolumn{5}{|c|}{ Vazão Máxima Efluente na cheia milenar $\left(\mathrm{m}^{3} / \mathrm{s}\right)=$} & 164,9 \\
\hline \multirow{3}{*}{$\begin{array}{c}\text { NA inicial } \\
(\mathrm{m})\end{array}$} & \multirow{3}{*}{$\begin{array}{c}\text { Volume de } \\
\text { Espera }\left(\mathrm{hm}^{3}\right)\end{array}$} & \multirow{3}{*}{$\begin{array}{c}\text { Volume de } \\
\text { Espera / Volume } \\
\text { Útil (\%) }\end{array}$} & \multicolumn{7}{|c|}{ NA máximo no reservatório $(\mathrm{m})$} \\
\hline & & & \multicolumn{7}{|c|}{ Vazão de Restrição ( $\left.\mathrm{m}^{3} / \mathrm{s}\right)$} \\
\hline & & & 7,0 & 10,0 & 20,0 & 30,0 & 40,0 & 50,0 & 60,0 \\
\hline 821,78 & 0,00 & 0,00 & 823,857 & 823,837 & 823,776 & 823,722 & 823,672 & 823,628 & 823,585 \\
\hline 821,50 & 2,41 & 3,50 & 823,591 & 823,572 & 823,515 & 823,465 & 823,420 & 823,380 & 823,342 \\
\hline 821,25 & 4,54 & 6,61 & 823,356 & 823,337 & 823,284 & 823,238 & 823,197 & 823,163 & 823,130 \\
\hline 821,00 & 6,66 & 9,68 & 823,120 & 823,103 & 823,054 & 823,013 & 822,977 & 822,949 & 822,922 \\
\hline 820,75 & 8,75 & 12,72 & 822,888 & 822,872 & 822,828 & 822,793 & 822,764 & 822,745 & 822,729 \\
\hline
\end{tabular}

Reservatório Jaguari-Jacareí

\begin{tabular}{|c|c|c|c|c|c|c|c|c|c|}
\hline \multicolumn{3}{|c|}{ NA máximo normal $(\mathrm{m})=$} & 844,00 & \multicolumn{5}{|c|}{ Cota de Coroamento da Barragem $(\mathrm{m})=$} & 847,00 \\
\hline \multicolumn{3}{|c|}{ Volume no NA máximo normal $\left(\mathrm{hm}^{3}\right)=$} & 1047,49 & \multicolumn{5}{|c|}{ NA máximo na cheia milenar $(\mathrm{m})=$} & 844,61 \\
\hline \multicolumn{3}{|c|}{ Volume Útil $\left(\mathrm{hm}^{3}\right)=$} & 808,04 & \multicolumn{5}{|c|}{ Vazão Máxima Efluente na cheia milenar $\left(\mathrm{m}^{3} / \mathrm{s}\right)=$} & $1.102,1$ \\
\hline \multirow{3}{*}{$\begin{array}{c}\text { NA inicial } \\
(\mathrm{m})\end{array}$} & \multirow{3}{*}{$\begin{array}{c}\text { Volume de } \\
\text { Espera }\left(\mathrm{hm}^{3}\right) \\
\end{array}$} & \multirow{3}{*}{$\begin{array}{c}\text { Volume de } \\
\text { Espera / Volume } \\
\text { Útil (\%) }\end{array}$} & \multicolumn{7}{|c|}{ NA máximo no reservatório (m) } \\
\hline & & & \multicolumn{7}{|c|}{ Vazão de Restrição ( $\left.\mathrm{m}^{3} / \mathrm{s}\right)$} \\
\hline & & & 50,0 & 75,0 & 100,0 & 125,0 & 150,0 & 175,0 & 200,0 \\
\hline 844,00 & 0,00 & 0,00 & 845,284 & 845,229 & 845,176 & 845,124 & 845,073 & 845,023 & 844,973 \\
\hline 843,50 & 24,67 & 3,05 & 844,802 & 844,746 & 844,692 & 844,639 & 844,587 & 844,536 & 844,485 \\
\hline 843,00 & 49,04 & 6,07 & 844,314 & 844,258 & 844,204 & 844,151 & 844,099 & 844,047 & 843,997 \\
\hline 842,50 & 73,10 & 9,05 & 843,834 & 843,777 & 843,721 & 843,667 & 843,613 & 843,561 & 843,510 \\
\hline 842,00 & 96,85 & 11,99 & 843,347 & 843,290 & 843,234 & 843,179 & 843,126 & 843,074 & 843,022 \\
\hline
\end{tabular}


nor do curso d'água é conformado por cheias de freqüências relativamente altas (tipicamente com recorrência entre dois e cinco anos). As vazões relacionadas acima, com exceção daquela relativa ao rio Jaguari, são da ordem de grandeza das vazões médias dos cursos de água e nitidamente não se enquadram na definição anterior. Conseqüentemente as vazões de restrição informadas pela SABESP são excessivamente conservadoras, o que poderia exigir volumes de espera expressivos, eventualmente até exagerados, e comprometer a capacidade de regularização dos aproveitamentos.

Dado que a seção transversal de um rio em condições naturais é usualmente estabelecida de forma que a calha principal tenha capacidade hidráulica correspondente às vazões com períodos de retorno entre 2 e 5 anos houve necessidade de determinar as vazões que melhor atendessem ao conceito de vazão de restrição. Desta forma, foi aplicada a modelagem chuva-vazão para chuvas com período de 2 anos permitindo obter as respectivas vazões de pico. Assim, esta vazão de pico seria um indicativo do limite em que, em condições naturais, o escoamento ficaria limitado à calha principal evitando a invasão das várzeas ou da calha secundária. As vazões de pico dos hidrogramas associados ao período de retorno de 2 anos foram:

- Jaguari-Jacareí: $150 \mathrm{~m}^{3} / \mathrm{s}$;

- Cachoeira: $60 \mathrm{~m}^{3} / \mathrm{s}$;

- Atibainha: $50 \mathrm{~m}^{3} / \mathrm{s}$;

- Paiva Castro: $30 \mathrm{~m}^{3} / \mathrm{s}$.

Verifica-se que as vazões de restrição obtidas por este procedimento são significativamente superiores àquelas fornecidas pela SABESP. Portanto, julgou-se necessário analisar os volumes de espera para uma faixa ampla de vazões de restrição, tendo como menor valor aquele fornecido pela SABESP e como limite superior vazões da ordem de grandeza daquelas obtidas pelo mencionado procedimento.

\section{Modelagem Computacional e Simulações}

Os estudos hidrológicos para análise do volume de espera dos reservatórios do Sistema Cantareira foram complementados analisando os aspectos de controle de cheias, entendidos como a capacidade de garantir vazões efluentes que não superem as vazões de restrição.

Para esta análise foram feitas a modelagem computacional e as simulações da operação dos reservatórios considerando os hidrogramas de cheia com período de retorno de 100 anos. As análises iniciais não consideraram volumes de espera nos reservatórios, de forma a avaliar os benefícios e verificar os NA máximos que seriam atingidos nesta operação. Posteriormente foram consideradas 4 alternativas de volume de espera, estabelecidas em função do volume do reservatório e das vazões de restrição. Assim, a condição inicial correspondeu à cota do NA que resulta no volume de espera considerado.

Para cada reservatório do Sistema Cantareira foram consideradas 7 alternativas de vazão de restrição e 4 alternativas de volume de espera que, acrescida da condição sem volume de espera, resultou em 35 simulações. Portanto, lembrando que o Sistema Cantareira é composto de 4 aproveitamentos, foram feitas 140 simulações da operação dos reservatórios para controle de cheias.

A operação de controle de cheias mantém vazões efluentes iguais às vazões de restrição limitadas à capacidade das estruturas hidráulicas. Desta forma, quando o NA do reservatório está baixo a capacidade hidráulica pode ser menor que a vazão de restrição.

A Tabela 15 apresenta uma síntese dos resultados obtidos nas 140 simulações de controle de cheias dos reservatórios do Sistema Cantareira. Para cada aproveitamento são informadas as principais características físicas do reservatório e os resultados das simulações para a cheia com período de retorno de 1.000 anos. Em seguida são apresentados os NA iniciais, os volumes de espera e a percentagem de comprometimento do volume útil do reservatório, fornecendo um indicativo do impacto na regularização. Para cada volume de espera e vazão de restrição são apresentados os NA máximos atingidos pelo reservatório na operação de controle de cheias para o hidrograma com período de retorno de 100 anos. A Tabela 15 apresenta em fundo vermelho (em destaque) os NA máximos atingidos na operação de garantia da vazão de restrição que superam as cotas de restrição para absorver a cheia milenar dos aproveitamentos do Sistema Cantareira.

\section{Avaliação do Volume de Espera}

Para estabelecer os volumes de espera dos reservatórios do Sistema Cantareira optou-se por um método que integrasse os aspectos de segurança hídrica dos aproveitamentos e o atendimento às vazões de restrição. A integração destes objetivos é necessária uma vez que, ao início da cheia, o operador do aproveitamento não conhece a magnitude da cheia afluente para tomar a decisão de operar para 
garantir a vazão de restrição ou a segurança da obra. Ressalta-se que diversos acidentes em barragens resultaram desta indecisão da operação.

Para esta integração dos objetivos foi feita a hipótese conservadora da concomitância da cheia com períodos de retorno de 100 e 1.000 anos. Isto equivale à operação optar por garantir a vazão de restrição e, posteriormente, verificar que deve optar por quebrar as restrições e garantir a segurança do aproveitamento. Assim, inicialmente, o reservatório é ocupado pelo volume necessário para garantir a vazão de restrição supondo a ocorrência da cheia com período de 100 anos para, posteriormente, ser acrescido do volume necessário para acomodar o hidrograma de projeto com período de retorno de 1.000 anos.

A Figura 15 representa de forma esquemática o método utilizado para a integração dos objetivos. Julgou-se adequado garantir uma borda-livre mínima de $1 \mathrm{~m}$ entre a cota da crista de coroamento da barragem e o NA máximo resultante da ocorrência simultânea das cheias com período de retorno de 100 e 1.000 anos. Então, foi determinada a cota que permitisse conter o volume máximo armazenado no reservatório na ocorrência do hidrograma com período de retorno de 1.000 anos, apresentado na 9 . linha da Tabela 16. Esta cota foi denominada cota de restrição para absorver a cheia milenar correspondendo ao máximo NA que pode ser atingido na operação para controle de cheias e garantia da vazão de restrição sem comprometer a segurança hidrológica da barragem. A Tabela 16 apresenta os parâmetros utilizados e os valores obtidos para a cota de restrição dos aproveitamentos do Sistema Cantareira.

A comparação das cotas de restrição dos aproveitamentos do Sistema Cantareira com os NA máximos atingidos na operação de garantia da vazão de restrição apresentadas na Tabela 15 permite identificar os volumes de espera necessários e/ou vazões de restrição que podem ser atendidas. A Tabela 15 apresenta em destaque os NA máximos atingidos na operação de garantia da vazão de restrição que superam as cotas de restrição dos aproveitamentos do Sistema Cantareira.

A análise da Tabela 15 permite concluir que:

- não é possível harmonizar os objetivos de garantir a segurança do aproveitamento Paiva Castro e as vazões de restrição, mesmo com um amplo volume de espera e vazões de restrição 10 vezes superiores àquelas indicadas pela SABESP;
- não há necessidade da utilização de volumes de espera para garantir, concomitantemente, a segurança hidrológica e as vazões de restrição para os aproveitamentos de Atibainha, Cachoeira e Jaguari-Jacareí.

- para evitar volumes de espera no aproveitamento Cachoeira é recomendável adequações que permitam elevar a vazão de restrição de 7,0 para $10,0 \mathrm{~m}^{3} / \mathrm{s}$. No entanto, ressalta-se que esta diferença é inexpressiva para a precisão dos modelos computacionais e mesmo para avaliações de campo.

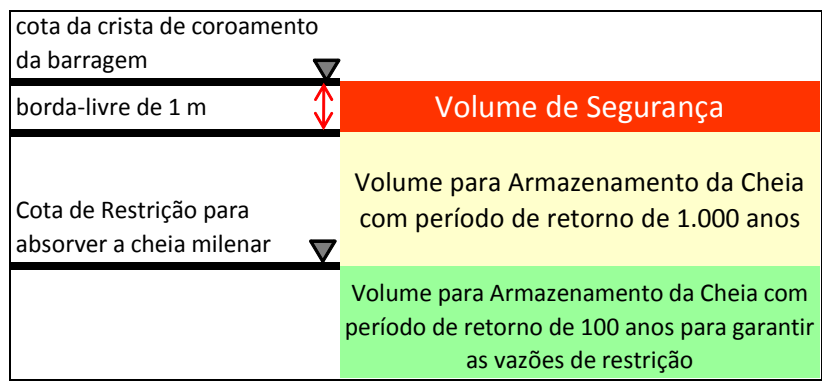

Figura 15 - Representação Esquemática do Método para Determinação da Cota de Restrição para Absorver o Hidrograma com Período de Retorno de 1.000 anos

Tabela 16- Determinação da Cota de Restrição para Absorver o Hidrograma com Período de Retorno de 1.000 anos

\begin{tabular}{|l|r|r|r|r|}
\hline Parâmetros & \multicolumn{1}{|c|}{$\begin{array}{l}\text { Jaguari- } \\
\text { Jacarei }\end{array}$} & \multicolumn{1}{c|}{ Cachoeira } & Atibainha & Paiva Castro \\
\hline Cota da Crista da Barragem $(\mathrm{m})$ & 847,00 & 827,28 & 791,00 & 750,00 \\
\hline Cota da Borda Livre $(\mathrm{m})$ & 846,00 & 826,28 & 790,00 & 749,00 \\
\hline NA Máximo normal $(\mathrm{m})$ & 844,00 & 821,78 & 786,86 & 745,61 \\
\hline & 844,61 & 824,18 & 787,82 & 748,16 \\
\hline NA máximo na cheia milenar $(\mathrm{m})$ & $1.149,10$ & 155,11 & 371,91 & 51,83 \\
\hline Volume na Cota da Borda Livre $\left(\mathrm{hm}^{3}\right)$ & $1.077,90$ & 136,91 & 319,94 & 46,73 \\
\hline Volume máximo na cheia milenar $\left(\mathrm{hm}^{3}\right)$ & $1.047,49$ & 115,71 & 298,52 & 33,05 \\
\hline Volume no NA máximo normal $\left(\mathrm{hm}^{3}\right)$ & 30,40 & 21,21 & 21,42 & 13,68 \\
\hline Volume máximo armazenado na cheia milenar $\left(\mathrm{hm}^{3}\right)$ & & & & \\
\hline & $1.118,70$ & 133,91 & 350,49 & 38,15 \\
\hline Volume mínimo a ser mantido $\left(\mathrm{hm}^{3}\right)$ & 845,41 & 823,84 & 789,12 & 746,64 \\
\hline Cota de Restrição para absorver a cheia milenar $(\mathrm{m})$ & & & & \\
\hline
\end{tabular}

\section{CONCLUSÕES}

Os estudos hidrológicos para avaliação dos volumes de espera dos aproveitamentos do Sistema Cantareira considerando os aspectos de segurança hidrológica das barragens e as vazões de restrição a jusante permitiram concluir que:

- os aproveitamentos têm capacidade hidráulica para absorver com segurança os hidro- 
gramas de projeto com período de retorno de 1.000 anos mantendo uma borda-livre, diferença entre a cota de coroamento da barragem e o NA máximo do reservatório, entre 1,84 e $3,18 \mathrm{~m}$;

- não há necessidade da utilização de volumes de espera para garantir, concomitantemente, a segurança hidrológica e as vazões de restrição para os aproveitamentos de Atibainha, Cachoeira e Jaguari-Jacareí;

- para evitar volumes de espera no aproveitamento Cachoeira é recomendável que a vazão de restrição seja igual ou superior a 10,0 $\mathrm{m}^{3} / \mathrm{s}$

- não é possível harmonizar os objetivos de garantir a segurança do aproveitamento Paiva Castro e as vazões de restrição, mesmo com um amplo volume de espera e vazões de restrição 10 vezes superiores àquelas indicadas pela SABESP. Desta forma recomenda-se que a operação de controle de cheias não seja adotada neste aproveitamento uma vez que poderá comprometer a segurança hidrológica do aproveitamento e, conseqüentemente, o rompimento da barragem.

\section{AGRADECIMENTOS}

Os autores agradecem à SABESP por autorizar a publicação deste artigo que resume os estudos hidrológicos para avaliação dos volumes de espera dos aproveitamentos do Sistema Cantareira desenvolvidos pelo LABSID - Laboratório de Sistemas de Suporte à Decisão do Departamento de Engenharia Hidráulica e Sanitária da Escola Politécnica da Universidade de São Paulo. No entanto as análises e conclusões apresentadas são dos autores e não devem ser atribuídas à SABESP.

\section{REFERÊNCIAS}

AZIMUTE (2008), Relatório Equações Consolidado Cota x Área x Volume Sistema Cantareira

CUNNANE, C. (1978) Unbiased plotting position - a review. Journal of Hydrology 37: 205-222

DATA OPER Sistema Cantareira (1991). SABESP, JNS

ELETROBRÁS (1987), Guia para Cálculo de Cheia de Projeto de Vertedores.
GRUBBS, F. and G. BECK (1972). Extension of sample sizes and percentage points for significance tests of outlying observations. Technometrics, 14(4): 847-854.

Hydrology Handbook. Second Edition. ASCE - American Society of Civil Engineers. (1996). Manuals and Reports on Engineering Pratice No. 28.

HOSKING, J.R.M. (1990) L-moments: Analysis and estimation of distribution using linear combination of order statistics, Journal of the Royal Statistical Society, Series $B, 52,105-124$.

KUTNER, A.S.; CONTE, A.E.; NITTA, T. (2001) - Análise Geológica e Caracterização dos solos para Avaliação do Coeficiente de Escoamento Superficial na Bacia do Alto Tietê - RMSP- XIV Simpósio Brasileiro de Recursos Hídricos, Aracaju..

MAGNI, N. L. G. e MERO, F. (1986) - Boletim n. 4 do CTH/DAEE "Precipitações Intensas no Estado de São Paulo".

Mapa Geológico do Estado de São Paulo - CPRM - v 2.0Esc. 1:750.000 - 2006

Mapa Geológico do Estado de Minas Gerais, CPRM / COMIG Esc. 1: $1.000 .000-2003$.

National Environmental Research Council (1975). U.K. Institute of Hydrology Flood Studies Report, Volume II, Wallingford, U.K.

OCCHIPINTI, AG e dos Santos, P.M. (1966). "Relação entre as Precipitações Máximas de 1 dia e de 24 horas na cidade de São Paulo".

PFAFSTETTER, O. (1982) "Chuvas Intensas no Brasil", Rio de Janeiro, DNOS, 2a . Edição.

SETZER,J., PORTO,R.L.L. (1979)- Boletim Técnico - DAEE "Tentativa de Avaliação do Escoamento Superficial de acordo com o solo e o seu recobrimento vegetal nas condições do Estado de São Paulo.".

SHERMAN, C.W. (1939) "Actual duration of one-day and twodays rain storms", Civil Engineering, 9:3.

SILVEIRA, A.L.L. (2005) Desempenho de Fórmulas de Tempo de Concentração em Bacias Urbanas e Rurais. Revista Brasileira de recursos Hídricos, vol. 10, n.1, 523, Jan/Mar.

STENDIGER, J.R., VOGEL, R.M., and FOUFOULAGEORGIOU, E. (1992) Frequency analysis of extreme events. In Handbook of Hydrology, edited by D.R. Maidment, Chapter 18, MacGraw-Hill, New York.

TUCCI, C.E.M. e outros (1995)- Drenagem Urbana. ABRH, UFRS.

U.S. DEPARTMENT OF AGRICULTURE, SOIL SURVEY MANUAL \# 18, Washington D.C., 1951, in WANIELISTA, M. - Hidrology and Water Quantity Control, J. Wiley, N.Y. -1990.

WALLIS, J.R. (1982). Hydrologic problems associated with oilshale development,. In Environmental Systems 
and Management, edited by S. Rinaldi, PP. 85-102. North-Holland, Amsterdam.

WHATELY, MARUSSIA. (2007) Cantareira 2006 : um olhar sobre o maior manancial de água da Região Metropolitana de São Paulo / Marussia Whately, Pilar Cunha. -- São Paulo : Instituto Socioambiental.

\section{Evaluation of Expected Flood Control Volume of the Cantareira System}

\section{ABSTRACT}

This paper presents hydrological and operational studies for flood control volume evaluation in the Cantareira System developments, considering dam safety and downstream flow restriction. The design hydrographs for this evaluation were set by applying the rainfall-runoff model. Physiographic characteristics were determined using cartographic base and image data for detailed pedological analysis and land use. Mathematical computer modeling was developed for reservoir operation simulation and flood control considering the restriction flows and hydrographs for a 100-year return period. The return period considered for dam safety was 1000 years. Finally, global analysis was performed for both design conditions.

Key-words: flood control volumes, dam safety, rainfallrunoff model. 